\title{
RELAÇÃO DOS SISTEMAS DE MONÇÃO COM AS VARIABILIDADES TROPICAL INTERANUAL E MULTI-DECENAL
}

\author{
SÂMIA REGINA GARCIA e MARY TOSHIE KAYANO
}

\author{
Instituto Nacional de Pesquisas Espaciais, Centro de Previsão de Tempo e Estudos Climáticos \\ São José dos Campos, SP, Brasil
}

samia.garcia@cptec.inpe.br, mary.kayano@cptec.inpe.br

Recebido Março 2008 - Aceito Setembro 2008

\begin{abstract}
RESUMO
A variabilidade da circulação tropical, com ênfase nos sistemas monçônicos, é examinada usando diversas variáveis para o período de 1948-1999. A componente monçônica do potencial de velocidade em $200 \mathrm{hPa}$ ( $\chi$-transiente), o desvio da média anual do desvio da média zonal, é o parâmetro chave usado para obter os modos monçônicos. A análise de Funções Ortogonais Empíricas (EOF) do $\chi$ transiente fornece dois modos separados. O primeiro modo descreve a variabilidade multi-decenal dos sistemas monçônicos da América do Sul e do Pacífico oeste. Esse modo, chamado monçônico multi-decenal (MMD), ocorre por todo o ano e contém a variabilidade multi-decenal relacionada à dinâmica da Oscilação Decenal do Pacífico (ODP). O segundo modo descreve as variações interanuais opostas entre a Ásia, África e oceano Índico e a região do oeste dos Estados Unidos, México e Pacífico leste. Esse modo, chamado modo interanual (MIA) apresenta algumas similaridades com o modo tropical interanual El Niño - Oscilação Sul. Alguns aspectos desses modos, incluindo sua circulação e características termodinâmicas são discutidas aqui. Finalmente, índices baseados nos padrões das configurações espaciais desses modos são construídos. A eficiência desses índices para fins de monitoramento é analisada. Logo, trata-se de um novo aspecto não proposto em trabalhos anteriores.
\end{abstract}

Palavras-Chave: Sistemas monçônicos, variabilidade multi-decenal, variabilidade interanual.

\begin{abstract}
RELATIONS OF THE MONSOON SYSTEMS TO THE TROPICAL MULTIDECADAL AND INTERANNUAL VARIABILITIES.

Tropical circulation variability, with emphasis on the monsoon systems is examined using several variables for the 1948-1999 period. The monsoon component in the $200 \mathrm{hPa}$ velocity potential (transient- $\chi$ ), the deviation from the annual mean of the zonal deviation field, is the key parameter used here to obtain the monsoon modes. The Empirical Orthogonal Function (EOF) analysis of the transient- $\chi$ yields two separate modes. The first mode describes the multi-decadal variability of the monsoon systems in South America and in the western Pacific. This mode, called the multi-decadal monsoon (MDM) mode, occurs throughout the year and contains the multi-decadal variability linked to the PDO dynamics. The second mode describes the opposite interannual variations of the Asian, African and Indian Ocean region and western United States, Mexico and eastern Pacific Ocean. This mode, called here the interannual mode (IAM) bears some similarities with the tropical interannual El Niño-Southern Oscillation mode. Some aspects of these modes, including their circulation and thermodynamic characteristics are discussed here. Finally, indices based on the loading patterns of these modes are constructed. The potential of these indices for monitoring tasks are analyzed. This is a new aspect not proposed in previous work.
\end{abstract}

Keywords: Monsoon systems, multi-decadal variability, interannual variability. 


\section{INTRODUÇÃO}

Sistemas monçônicos são partes inerentes à circulação atmosférica sobre os continentes tropicais e subtropicais e áreas oceânicas adjacentes, particularmente no hemisfério leste. Considerando a variação sazonal da precipitação como um dos principais aspectos que diferencia uma região monçônica das outras, a Ásia e a América tropical são as principais regiões do globo com características monçônicas. Dois sistemas monçônicos são notados na Ásia, um sobre seu setor leste (Monção do leste da Ásia) e o outro sobre seu setor sul (Monção da Índia) (e.g., Lau e Li, 1984; Tao e Chen, 1987). No hemisfério oeste, dois sistemas monçônicos são bem conhecidos, o da América do Sul e o da América do Norte (e.g., Mechoso et al., 2005). Os aspectos meteorológicos e climatológicos desses sistemas, assim como suas relações com o El Niño - Oscilação Sul (ENOS) têm sido bastante documentados. Uma revisão desses aspectos é encontrada em uma série de artigos apresentados no "Third International Workshop on Monsoons", organizado pela Organização Mundial de Meteorologia (e.g., Goswami, 2005; Wang et al., 2005; Ding et al., 2005; Mechoso et al., 2005; Ropelewski et al., 2005; Grimm et al., 2005).

Estudos recentes forneceram evidências diagnósticas da variabilidade multi-decenal dos sistemas monçônicos, que tem sido interpretada em termos de teleconexões com a Oscilação (inter-) Decenal do Pacífico (ODP). O modo ODP está envolvido na variabilidade multi-decenal do Pacífico Norte (Mantua et al., 1997). Os padrões anômalos relacionados à ODP de temperatura da superfície do mar (TSM), pressão ao nível do mar (PNM) e vento em superfície no Pacífico são bastante similares aos padrões correspondentes ao modo ENOS (Mantua et al., 1997; Zhang et al., 1997; Garreaud e Battisti, 1999; Mestas-Nuñez e Enfield, 2001). A fase positiva (regime quente) da ODP é caracterizada por um sistema de baixa pressão Aleutiana anomalamente profunda, anomalias negativas de TSM nas partes central e oeste do Pacífico norte e anomalias positivas de TSM ao longo da costa oeste das Américas, assim como no Pacífico tropical central e leste (e.g., Mantua et al. 1997). A fase negativa (regime frio) da ODP apresenta padrões quase reversos. Em adição, a configuração das anomalias de PNM no setor do Atlântico associado com o modo ODP assemelha-se com o padrão da Oscilação do Atlântico Norte (OAN) (Mo e Häkkinen, 2001).

O conceito de ODP utilizado aqui é diferente daquele do modo tipo ENOS de baixa freqüência. O modo tipo ENOS de baixa freqüência mostra sinais mais dominantes no Pacífico tropical e apresenta oscilações com períodos de 20-30 anos (e.g., Zhang et al., 1997; Zhang et al., 1998). O modo ODP, por outro lado, tem sinal tanto no Pacífico tropical quanto em latitudes médias no Pacífico Norte e é dominado por oscilações com período de 50 anos (Minobe, 2000; Liu et al., 2002). Consistente com essa escala de tempo, Mantua et al. (1997) observou o regime frio da ODP durante os períodos de 1900-1924 e 19471976 e, o regime quente, durante o período de 1925-1946 e de 1977 a meados de 1990.

Vários trabalhos documentaram as flutuações multidecenais da precipitação da monção de verão da Índia, caracterizada por épocas de precipitação acima e abaixo da normal por aproximadamente 30 anos (e.g., Mooley e Parthasarathy, 1984; Parthasarathy et al., 1994; Krishnamurthy e Goswami, 2000). Observou-se em grande parte da Índia precipitação acima (abaixo) da normal durante os períodos de 1871-1900 e 19311960 (1901-1930 e 1961-1990) (Krishnamurthy e Goswami, 2000). Krishnamurthy e Goswami (2000) também notaram que os padrões globais de TSM e PNM, associados com variações multi-decenais da monção de verão da Índia mostram algumas similaridades do modo ODP.

A precipitação sobre o leste da Ásia também mostra variabilidade multi-decenal (Hu, 1997; Chang et al., 2000a; 2000b; Wu e Wang, 2002). A precipitação relacionada ao ENOS no nordeste da China foi abaixo (acima) da normal, enquanto no vale do rio Yangtze foi acima (abaixo) da normal durante o período de 1962-1977 (1978-1993) (Wu e Wang, 2002). Wu e Wang (2002) atribuíram a mudança na relação entre precipitação no leste da Ásia e o ENOS, a mudanças na localização e intensidade da convecção anômala sobre o oeste do Pacífico Norte depois de 1976.

Vários trabalhos forneceram evidências de que a ODP modula a variabilidade interanual da monção da América do Norte (Gershunov e Barnett, 1998; McCabe e Dettinger, 1999; Higgins e Shi, 2000; Castro et al., 2001; Barlow et al., 2001; Gutzler et al., 2002; Chelliah e Bell, 2004; Brown e Comrie, 2004). De fato, sinais típicos de El Niño (La Niña) caracterizados por condições secas/úmidas (úmidas/secas) sobre o noroeste/sudoeste da América do Norte, tendem a ser fortes e consistentes durante o regime quente (frio) da ODP (Gershunov e Barnett, 1998). Em adição, Castro et al. (2001) sugeriram que um evento El Niño (La Niña) sob a fase positiva (negativa) da ODP favorece uma crista monçônica mais fraca (forte) e deslocada para sul (norte).

Variações decenais e tendências de longo prazo têm sido documentadas para parâmetros hidrometeorológicos na América do Sul (Dias de Paiva e Clarke, 1995; Krepper e Sequeira, 1998; Robertson e Mechoso, 1998; 2000; Zhou e Lau, 2001; Paegle e Mo, 2002; Chelliah e Bell, 2004; Marengo, 2004; Kayano e Andreoli, 2004; Andreoli e Kayano, 2005). Zhou e Lau (2001) encontraram um modo decenal de precipitação de verão austral com as maiores correlações sobre o noroeste da América do Sul e anomalias de sinais opostos sobre o nordeste do Brasil para o período de 1979-1995. Vários autores notaram um aumento 
de precipitação sobre a bacia Amazônica durante o período de 1980-1990 relativo a de 1950-1960 (Chu et al., 1994; Kumar et al., 1999; Chen et al., 2001). Andreoli e Kayano (2005) encontraram que anomalias negativas de precipitação sobre a América do Sul relacionadas ao El Niño, em particular sobre seu setor noroeste, mostram maiores magnitudes para a fase quente da ODP quando comparadas às da fase fria da mesma.

No que concerne à variabilidade dos sistemas monçônicos em uma escala de tempo multi-decenal, poucos estudos trataram de suas teleconexões globais. Um desses estudos é aquele conduzido por Chelliah e Bell (2004), que forneceram uma visão global da variabilidade tropical multi-decenal para o campo de potencial de velocidade em $200 \mathrm{hPa}$, taxa de precipitação e temperatura da superfície. Esse estudo é baseado na análise de Funções Ortogonais Empíricas (EOF) das anomalias sazonais de potencial de velocidade em $200 \mathrm{hPa}$ filtrado com o filtro passa-baixa com uma média corrida de 5 anos. Eles encontraram variações multi-decenais coerentes na convecção tropical e temperatura da superfície em 4 regiões: a região monçônica do oeste da África, o Pacífico tropical central, a bacia Amazônica e o oceano Índico tropical. Esse modo tropical multi-decenal do potencial de velocidade em $200 \mathrm{hPa}$ filtrado com filtro passabaixa para o verão (de dezembro a fevereiro) e os compostos das anomalias de potencial de velocidade em $200 \mathrm{hPa}$ para essa mesma estação, para 1978-1999 menos 1950-1977, do residual de não-ENOS na região do Niño-3 fornecido por Paegle et al. (2002) mostram padrões quase similares.

Embora o conhecimento da variabilidade multi-decenal dos sistemas monçônicos deva ser usado para finalidades de monitoramento e previsão climática, essa variabilidade ainda não é bem compreendida. Assim, o presente trabalho examina aspectos dessa variabilidade multi-decenal e, ainda, da variabilidade interanual dos sistemas monçônicos, assim como as características dinâmicas e termodinâmicas associadas considerando análises quase globais de várias variáveis. Nesse trabalho, os modos relacionados à monção são derivados da componente transiente do potencial de velocidade em $200 \mathrm{hPa}$, em vez de considerar a própria variável, como feito em análises anteriores (Chelliah e Bell, 2004; Paegle et al., 2002). Outra diferença é que nenhum processo de filtragem é usado aqui.

\section{DADOS E METODOLOGIA}

Parte dos dados usados neste trabalho foi obtida do arquivo da reanálise do NCEP/NCAR (Kalnay et al., 1996) e são médias mensais de: temperatura do ar, potencial de velocidade $(\chi)$ em $200 \mathrm{hPa}$, velocidade vertical em $500 \mathrm{hPa}, \mathrm{PNM}$ e água precipitável. Os dados de $\chi \mathrm{em} 200 \mathrm{hPa}$ estão em pontos de grade Gaussiana com espaçamento de aproximadamente $1,875^{\circ} \mathrm{em}$ longitude e latitude; os demais, estão em pontos de grade com resolução de $2,5^{\circ}$ de longitude e de latitude. Também foram usados dados mensais de TSM, os quais foram reconstruídos e estendidos por Smith e Reynolds (2003) para o período de 1854-2000 e estão em pontos de grade com resolução de $2^{\circ}$ de latitude e de longitude. Todos os dados são obtidos para o período de janeiro de 1948 a dezembro de 1999, exceto os dados de $\chi$ em $200 \mathrm{hPa}$, que são obtidos para o período de janeiro de 1948 a julho de 2005. O período base para as climatologias, EOF e compostos, é de janeiro de 1948 a dezembro de 1999. Os dados de $\chi$ em $200 \mathrm{hPa}$ para 6 anos adicionais a este período base servirão para testar o uso de um índice proposto para monitoramento de monção. Assim, estes 6 anos não são incluídos na climatologia e nem nos demais cálculos (EOF e composições).

Assume-se que a componente da circulação de Hadley está contida na média zonal de $\chi$ para cada latitude (Krishnamurti, 1971; Krishnamurti et al., 1973). Subtraindo-se a média zonal do $\chi$ de cada ponto de grade daquela latitude gera-se o campo de $\chi^{*}(\mathrm{t}, \mathrm{x}, \mathrm{y})$, o qual contém as componentes de Walker e monçônica referidos como componentes de "eddy" (Tanaka et al., 2004). Os símbolos x, y, e t referem-se à longitude, latitude e tempo, respectivamente. Em cada ponto de grade, calcula-se para cada ano a média do ano inteiro de $\chi^{*}(\mathrm{t}, \mathrm{x}, \mathrm{y})$. Assume-se que a circulação de Walker está incluída na média geral de $\chi^{*}$ $(\mathrm{t}, \mathrm{x}, \mathrm{y})$ sobre todos os anos do período base. Finalmente, para cada ponto de grade e mês é removida de $\chi^{*}(\mathrm{t}, \mathrm{x}, \mathrm{y})$ sua média geral, gerando o campo de $\chi^{*}(\mathrm{t}, \mathrm{x}, \mathrm{y})$, o qual contém a circulação monçônica. Esse método não remove a componente interanual da circulação de Walker no campo de $\chi^{*}(\mathrm{t}, \mathrm{x}, \mathrm{y})$. Como o interesse aqui é na circulação monçônica, apenas o campo de $\chi$ * $(\mathrm{t}, \mathrm{x}, \mathrm{y})$ é analisado. Esse campo é referido como um potencial de velocidade transiente ( $\chi$-transiente), para simplificação, e é obtido para o período de 1948-2005, que é mais longo do que o período base já que um índice para fins de monitoramento será calculado posteriormente.

Anomalias mensais do $\chi$-transiente, TSM, temperatura do ar, PNM, velocidade vertical em $500 \mathrm{hPa}$ e água precipitável são calculadas em cada ponto de grade como desvios das médias mensais de 1948-1999. As séries de anomalias em cada ponto de grade são padronizadas pelos correspondentes desvios padrão mensais. Esses cálculos são feitos para a área global entre $80^{\circ} \mathrm{N}$ e $80^{\circ} \mathrm{S}$. Anomalias mensais do $\chi$-transiente são obtidas para o período de 1948-2005.

Os modos dominantes para o campo de anomalia do $\chi$-transiente na banda global entre $60^{\circ} \mathrm{N}$ e $40^{\circ} \mathrm{S}$ para o período 1948-1999 são obtidos submetendo este campo a análises de EOF (baseada na matriz de correlação). Tal análise é feita considerando séries de anomalias mensais de $\chi$-transiente durante todo o ano, sem a separação por meses ou estações do ano. Para diminuir o tempo computacional, 
a resolução espacial dessas séries é reduzida para $3,75^{\circ}$ de latitude e longitude. A significância física desses modos é testada usando o método proposto por North et al. (1982). Os autovetores correspondentes à análise de EOF são apresentados como padrões de correlação. Para verificar a significância estatística dessas correlações, o número de graus de liberdade é estimado para cada modo dividindo o comprimento da série das componentes principais (PC) pelo intervalo de tempo de duas realizações independentes (a defasagem necessária para se obter coeficientes de autocorrelação nas séries temporais de PC próximas a zero). Os graus de liberdade estimados para o primeiro e segundo modo são 4 e 40 , respectivamente. $\mathrm{O}$ teste $\mathrm{t}$ de Student para 4 graus de liberdade fornece o valor limítrofe de aproximadamente 0,80 para as correlações serem significativas no nível de confiança de $95 \%$. O mesmo teste aplicado para 40 graus de liberdade, resulta no valor limítrofe de correlação de 0,39 para serem significativas no nível de confiança de $99 \%$. Logo, as correlações absolutas consideradas significantes nos padrões da EOF, são aquelas maiores ou iguais a 0,80 e 0,40 para o primeiro e segundo modo, respectivamente.

Como as séries temporais do PC fornecem as variações temporais do modo correspondente, as médias sazonais dessas séries são usadas para a seleção dos casos para os compostos das anomalias de TSM, temperatura do ar, PNM, velocidade vertical em $500 \mathrm{hPa}$ e água precipitável para um dado modo. Os casos incluídos em cada composto são selecionados usando-se o valor limítrofe de $\pm 0,5$ desvio padrão dos valores sazonais do PC. Compostos são obtidos para verão e inverno austral (de dezembro a fevereiro - DJF, e de junho a agosto - JJA, respectivamente). Os compostos negativos (positivos) referemse aos casos com PC menores que -0,5 (maiores que 0,5) desvio padrão. Para verificar a significância estatística dos compostos, o número de graus de liberdade é considerado o número de casos incluídos em cada composto. Assume-se que uma variável $\mathrm{X}$ com $n$ valores e desvio padrão $\mathrm{S}$ tenha uma distribuição normal. Assim, apenas os valores absolutos excedendo $t_{\alpha(n-1)} S / \sqrt{(n-1)}$ são estatisticamente significativos (Panofsky e Brier, 1968). O nível de confiança de $95 \%$ é usado. As referências para "estações", daqui em diante, são no contexto do hemisfério sul. Para propósitos de monitoramento climático, índices monçônicos são obtidos pela projeção do campo de anomalia do $\chi$-transiente (do período completo de 1948 a 2005) nos padrões das configurações espaciais para modos selecionados. Esse método é similar ao utilizado por Kayano e Kousky (1993) para a Oscilação Sul. A diferença é que, neste caso, o campo de anomalia do $\chi$-transiente não passou por nenhum processo de filtragem temporal.

a) EOF01
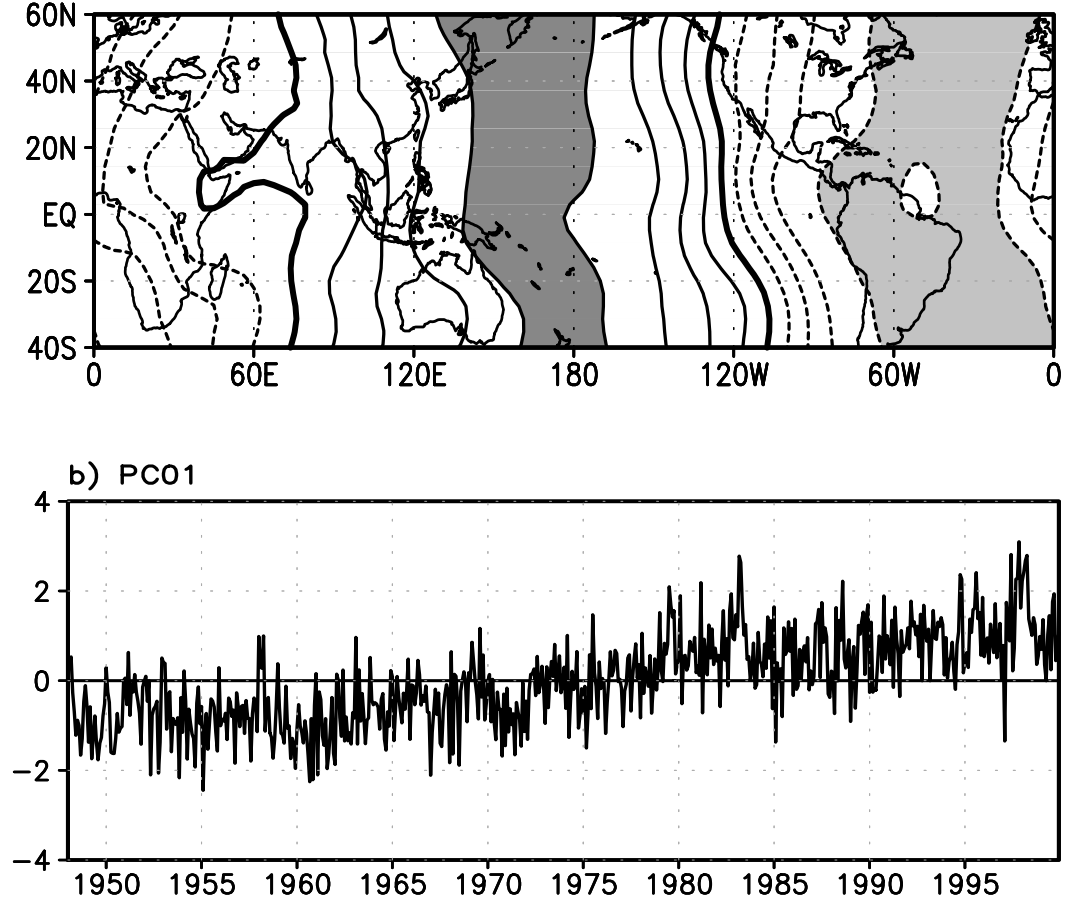

Figura 1 - Primeiro modo da EOF de $\chi$-transiente para o período de 1948-1999: a) configuração espacial e b) componente principal. O intervalo de contorno é de 0,20 , com o contorno mais espesso sendo o de zero. Os contornos pontilhados (contínuos) indicam valores negativos (positivos), com áreas hachuradas claras (escuras) indicando valores menores (maiores) que $-0,8(0,8)$. 


\section{RESULTADOS}

\subsection{Modos dominantes de $\chi$-transiente}

O primeiro e o segundo modo da EOF das anomalias do $\chi$-transiente explicam $37,7 \%$ e $27,7 \%$ da variância total para essa variável, respectivamente. De acordo com o método proposto por North et al. (1982), os autovalores correspondentes são bem separados um do outro. O primeiro modo apresenta as maiores correlações em dois centros meridionalmente alongados, um no setor incluindo a América do Sul tropical e oceano Atlântico, com valores negativos, e o centro de sinal oposto no Pacífico oeste (Figura 1a). Em ambos os centros, os valores absolutos excederam 0,80 . As maiores correlações negativas estendendo-se da América do Sul às latitudes médias do Atlântico Norte sugerem relações desse modo com as variações da OAN. Grandes valores negativos de correlação também são observados na América Central e sobre o leste e sul dos Estados Unidos. Entretanto, regionalmente na América do Sul a variância explicada de $64 \%$ contrasta com a da América do Norte, onde ela varia de $16 \%$ até $50 \%$. A variância regional é estimada considerando-se o quadrado da correlação, uma vez que os padrões estão expressos em termos de correlações.
O primeiro modo claramente reflete a componente multi-decenal da circulação atmosférica em altos níveis. A série temporal do PC01 (Figura 1b) mostra uma reversão de sinal negativo para positivo em meados da década de 1970, quando a alteração climática brusca multi-decenal ocorreu (Mantua et al., 1997). Essa reversão de sinal do PC01, também é indicativa de uma oscilação com um período de 50-60 anos, o período da ODP (Minobe, 1999; 2000). Para PC01 positivo (negativo), o escoamento divergente (convergente) anômalo em altos níveis sobre a América do Sul tropical é compensado pelo escoamento convergente (divergente) anômalo em altos níveis no Pacífico oeste. Assim, o primeiro modo da EOF descreve a circulação divergente oposta em altos níveis sobre a América do Sul e o Pacífico oeste, manifestada em uma escala de tempo multidecenal. Esse modo, daqui em diante, é referido como o modo monçônico multi-decenal (MMD).

O segundo modo da EOF mostra correlações dominantes com sinais contrários sobre a Ásia, parte da África e oceano Índico (correlações positivas) e sobre a área que se estende do Pacífico leste ao oeste dos Estados Unidos/México (correlações negativas) (Figura 2a). A série temporal do PC correspondente mostra oscilações interanuais com períodos de aproximadamente 4-5 anos (Figura 2b). Para PC02 positivo (negativo), o campo

a) EOF02

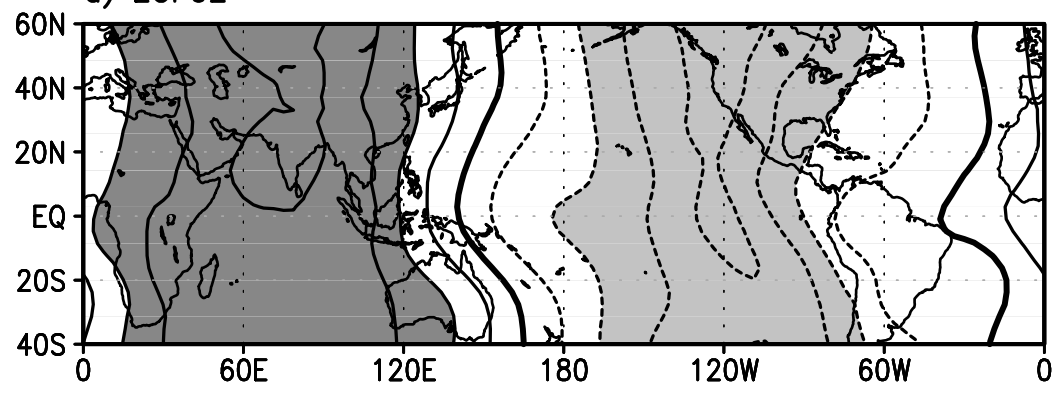

b) $\mathrm{PCO} 2$

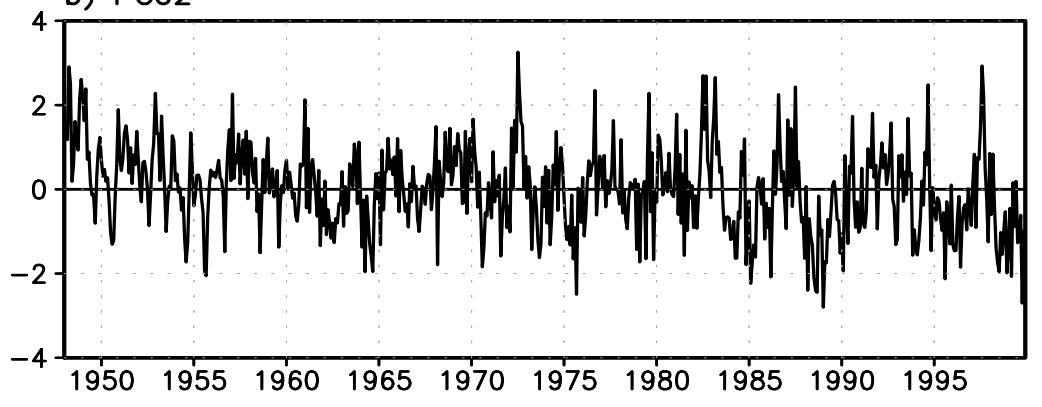

Figura 2 - Segundo modo da EOF de $\chi$-transiente para o período de 1948-1999: a) configuração espacial e b) componente principal. As convenções gráficas são as mesmas da Figura 1, exceto que áreas hachuradas claras (escuras) indicam valores menores (maiores) que -0,4 (0,4). 
de divergência anômala em altos níveis descreve o escoamento divergente (convergente) sobre o oeste dos Estados Unidos, México e Pacífico leste e escoamento convergente (divergente) sobre a Ásia, África e oceano Índico. Assim, o segundo modo ilustra o comportamento oposto da divergência e convergência em altos níveis entre essas regiões ocorrendo em uma escala de tempo interanual. Esse modo, daqui em diante, será referido como o modo interanual (MIA).

A série temporal média do PC dos dois primeiros modos para os meses de verão (DJF) e inverno (JJA) fornecem uma melhor ilustração de suas variações temporais assim como de suas diferenças sazonais (Figura 3). As variações de alta freqüência no PC01 são mais evidentes durante o verão (Figuras $3 \mathrm{a}$ e $3 \mathrm{~b}$ ). A reversão de sinal do PC01 em meados da década de 1970 é mais notada no inverno do que no verão (Figuras 3a e 3b). O PC01 de verão mostra pequenas magnitudes antes de 1952, valores negativos de 1953 a 1976 e valores positivos de 1977 em diante (Figura 3a). Por outro lado, os valores do PC01 de inverno são negativos antes de 1972, positivos com pequenas magnitudes de 1972 a 1978 e positivos de 1979 em diante (Figura 3b).

O PC02 de verão mostra sinais alternantes na escala de tempo de 1-3 anos durante o período de 1961-1982, valores predominantemente positivos antes de 1960 e negativos de 1983 em diante (Figura 3c). Os valores de PC02 positivos antes de 1960 e os negativos depois de 1983 ocorrem em seqüências de 4 a 7 anos. Logo, o PC02 de verão contém variações nas escalas de tempo interanual e multi-decenal. Por outro lado, o PC02 de inverno mostra flutuações interanuais bem definidas com vários valores positivos (negativos) ocorrendo durante anos de

a) PC01-DJF
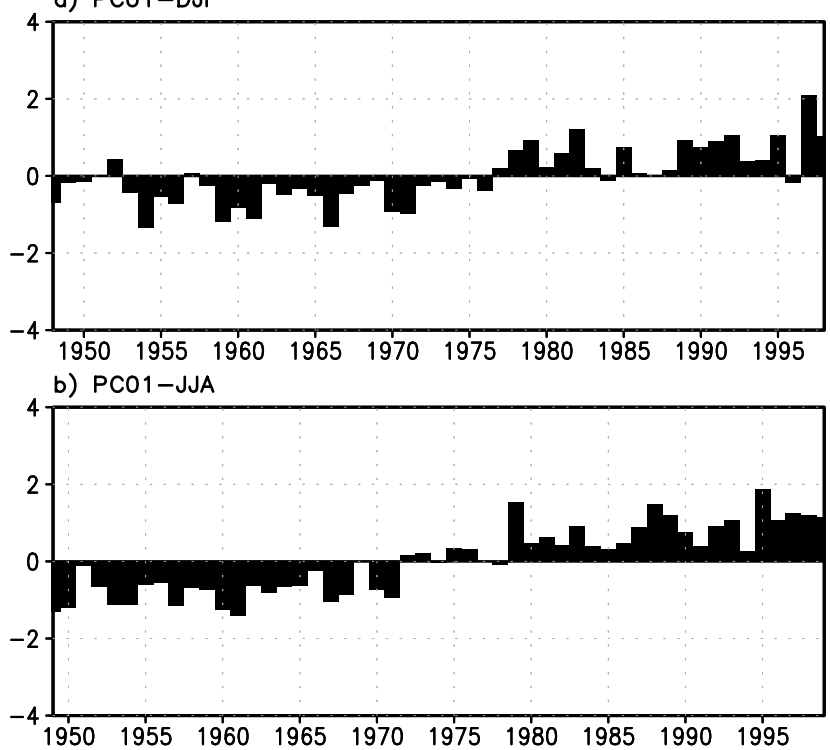

início de eventos El Niño (La Niña) (Figura 3d). Esses casos de anos de início de El Niño (La Niña) são 1951, 1957, 1965, 1972, 1982, 1986, 1987, 1991, 1994 e 1997 (1950, 1954, 1955, 1962, 1964, 1970, 1973, 1988, 1995 e 1998).

Comparando os resultados acima com a análise sazonal do potencial de velocidade em $200 \mathrm{hPa}$ com um filtro passabaixa aplicado feita por Chelliah e Bell (2004), algumas similaridades são evidentes. O modo MMD e suas variações de verão são bem similares ao padrão dominante e PC do modo multi-decenal tropical de verão encontrado por eles (Figura 4c deles). O modo MIA e suas variações de inverno também são similares ao padrão dominante e PC do modo interanual tropical de inverno (ENOS) encontrado por eles (Figura 3d deles). Assim, os modos sazonais encontrados por eles ocorrem todo o ano, mas variam sazonalmente.

\subsection{Modo Monçônico Multi-Decenal (MMD)}

É importante notar que todos os casos negativos (positivos) incluídos nos compostos associados com o modo MMD estão no período anterior (posterior) a 1975, quando a fase negativa (positiva) da ODP ocorreu. A Tabela 1 lista os anos considerados nesses compostos. Para compostos de verão, o ano refere-se a dezembro.

\subsubsection{Compostos de verão para o modo MMD}

O composto negativo de verão das anomalias de TSM mostra um padrão robusto e espacialmente coerente com valores de TSM menores que a média nos oceanos tropicais Índico
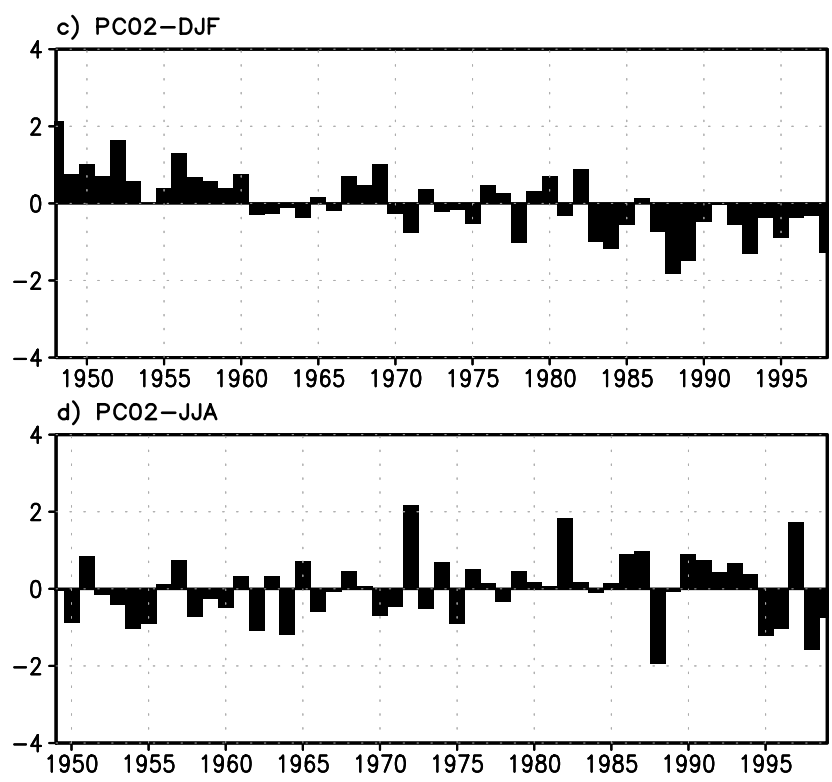

Figura 3 - Séries temporais médias da componente principal para os meses de verão (DJF) e inverno (JJA): a) PC01 para DJF; b) PC01 para JJA; c) PC02 para DJF; e d) PC02 para JJA. 
DJF (PCO1<-0.5)

a) Temperatura da Superficie do Mar

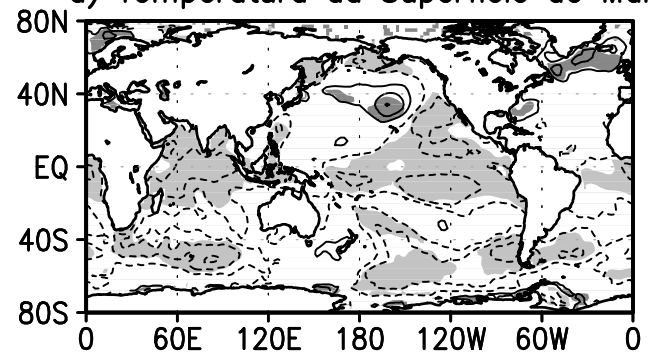

b) Temperatura do ar

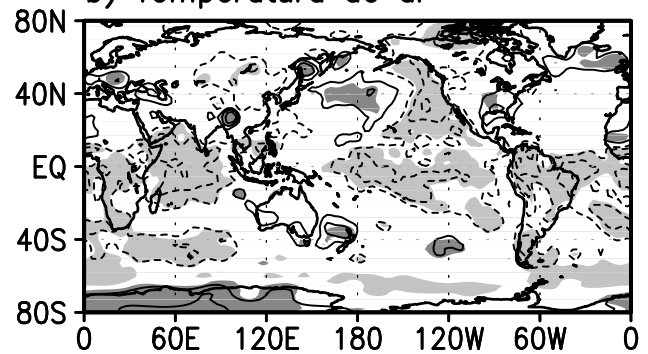

c) Pressao ao Nivel do Mar

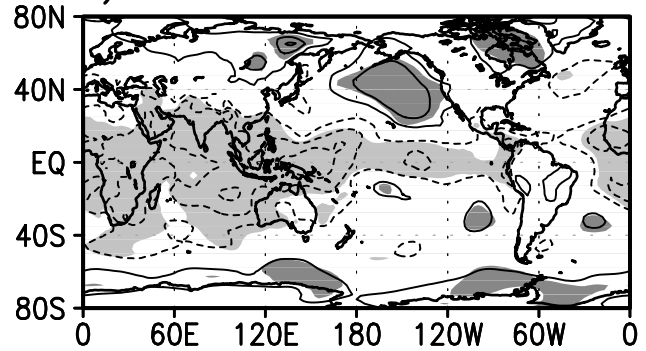

d) Velocidade Vertical

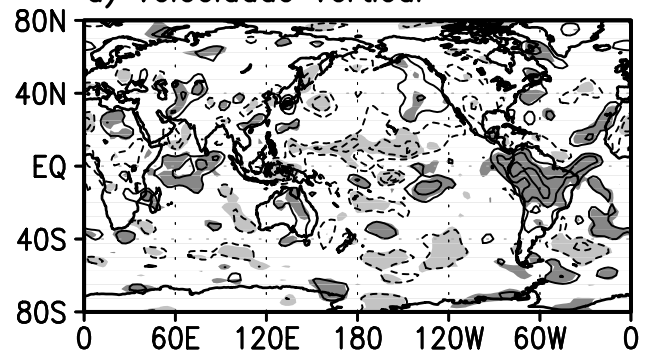

e) Agua Precipitavel

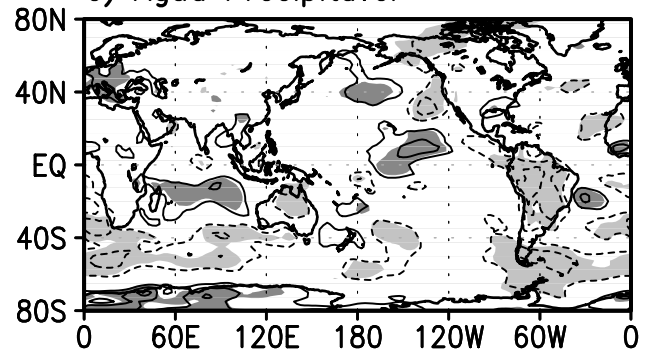

DJF (PC01 > 0.5)

f) Temperatura da Superficie do Mar

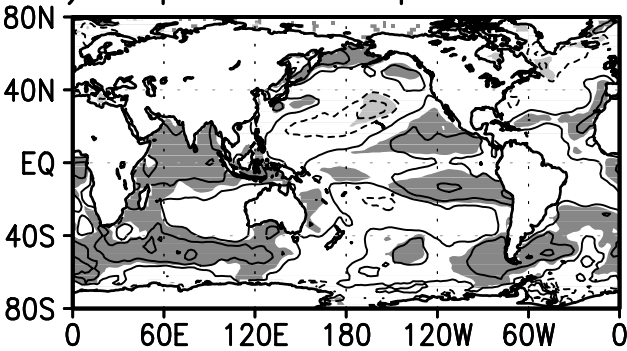

g) Temperatura do ar

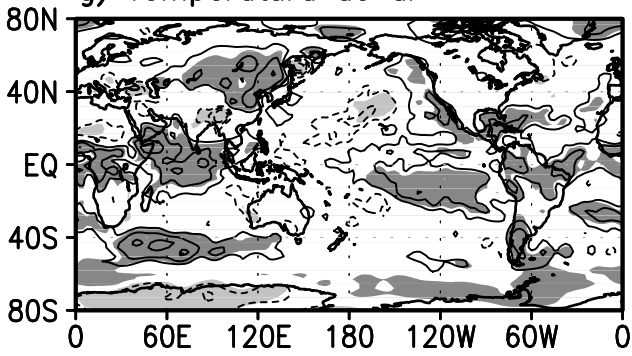

h) Pressao ao Nivel do Mar

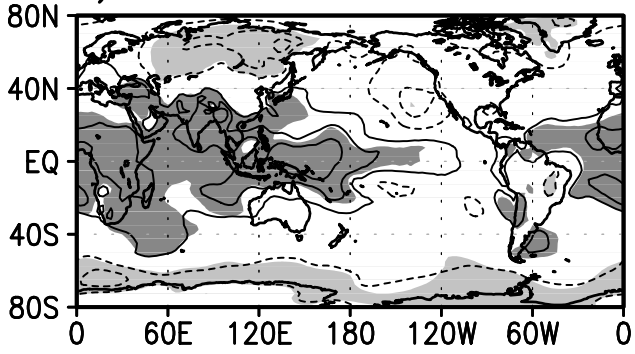

i) Velocidade Vertical
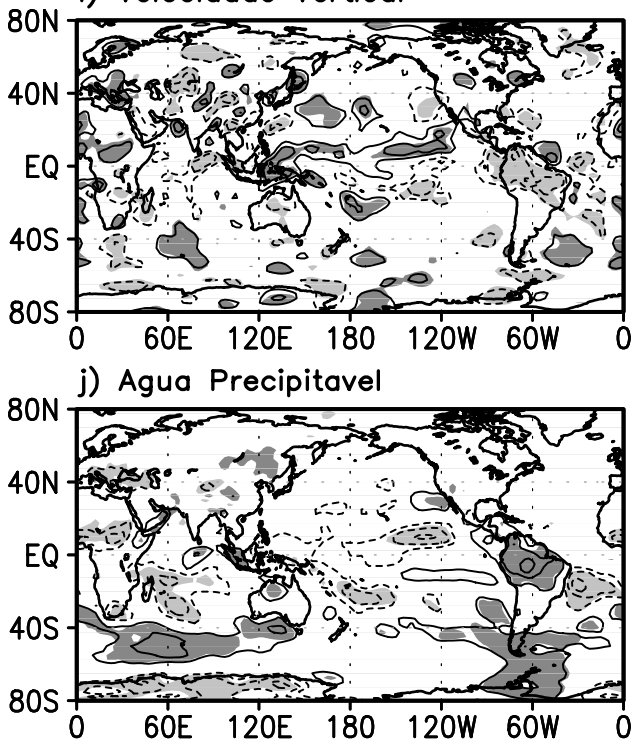

Figura 4 - Compostos das anomalias de verão (DJF) para PC01 menor que -0,5 desvio padrão para: a) TSM, b) temperatura do ar à superfície, c) PNM, d) velocidade vertical e e) água precipitável. Compostos das anomalias de verão (DJF) para PC01 maior que 0,5 desvio padrão para: f) TSM, g) temperatura do ar à superfície, h) PNM, j) velocidade vertical e j) água precipitável. O intervalo de contorno é de 0,3 desvio padrão, com contornos negativos (positivos) tracejados (contínuos). O contorno de zero foi omitido. Áreas hachuradas abrangem valores significativos no nível de confiança de $95 \%$. 
e Pacífico e nas áreas oceânicas ao sul de $40^{\circ} \mathrm{S}$, assim como maiores que a média no Pacífico central Norte e no Atlântico Norte (Figura 4a). O composto positivo para a mesma estação apresenta um padrão com sinal contrário (Figura 4f). Esses compostos são bastante similares aos padrões de anomalias de TSM do modo ODP descrito por Mantua et al. (1997).

Coerentemente, o composto negativo (positivo) de temperatura do ar mostra o ar em baixos níveis mais frio (quente) que a normal sobre as regiões oceânicas com anomalias negativas (positivas) de TSM (Figuras 4b e 4g). Em adição, valores de temperatura do ar em baixos níveis menores (maiores) que a normal para o composto negativo (positivo) são observados sobre o Atlântico tropical e equatorial sul, e ainda, sobre algumas regiões continentais. Para o composto negativo, o ar em baixos níveis mais frio do que a média é encontrado sobre grande parte da América do Sul, na África equatorial e sul e no leste da Ásia. Para o composto positivo, anomalias positivas de temperatura do ar são encontradas sobre essas mesmas regiões continentais e sobre a China. Portanto, o aquecimento (resfriamento) do ar à superfície relacionado à ODP não está restrito a regiões oceânicas, mas estendem-se a regiões continentais adjacentes.

Curiosamente, o composto negativo (positivo) das anomalias de PNM exibe uma forte estrutura zonal com pressão abaixo (acima) da média nos trópicos e anomalias de PNM de sinal oposto sobre o Pacífico norte (norte da Ásia e Rússia) (Figuras 4c e 4h). Para o composto negativo (positivo), os valores mais intensos de pressão abaixo (acima) da normal nos trópicos são localizados na área complementar ao maior resfriamento (aquecimento) do ar em baixos níveis. Essa área estende-se do oceano Índico tropical leste à região de Papua/ Nova Guiné, onde pequenos valores de anomalias positivas (negativas) de temperatura do ar prevalecem (Figuras $4 \mathrm{~b}, 4 \mathrm{~g}$, 4c e 4h).

Similar aos compostos das anomalias de TSM e temperatura do ar, os compostos positivos e negativos de velocidade vertical em $500 \mathrm{hPa}$ mostram padrões de sinais contrários. Para o composto negativo de verão dessa variável, movimento descendente anômalo sobre a bacia Amazônica e áreas adjacentes, e no oceano Índico equatorial, é compensado por movimento ascendente anômalo no Pacífico central ao longo de $10^{\circ} \mathrm{N}$ (Figuras $4 \mathrm{~d}$ e $4 \mathrm{i}$ ). O movimento descendente (ascendente), sobre o setor monçônico da América do Sul, é consistente com o escoamento convergente (divergente) anômalo dominante em altos níveis e temperatura menor (maior) que a normal notada nesse setor durante o período anterior (posterior) a 1975 (Figuras 4b, 4g, 4d e 4i).

Em adição, os compostos de água precipitável mostram padrões muito coerentes com um aumento (diminuição) de água precipitável ocorrendo em áreas com movimento ascendente (descendente) anômalo, exceto no Atlântico tropical e no Índico extratropical (Figuras 4d, 4i, 4e e 4j). O composto negativo de água precipitável mostra redução da mesma sobre a América do Sul e sobre extensivas áreas ao sul de $30^{\circ} \mathrm{S}$, assim como

Tabela 1 - Anos usados nos compostos para o PC01.

\begin{tabular}{|c|c|c|c|}
\hline \multicolumn{2}{|c|}{$\mathrm{PC} 01>0,5$} & \multicolumn{2}{|c|}{ PC01<-0,5 } \\
\hline DJF (12) & JJA (14) & DJF (11) & JJA (20) \\
\hline 1978 & 1979 & 1948 & 1949 \\
\hline 1979 & 1981 & 1954 & 1950 \\
\hline 1981 & 1983 & 1955 & 1952 \\
\hline 1982 & 1987 & 1956 & 1953 \\
\hline 1985 & 1988 & 1959 & 1954 \\
\hline 1989 & 1989 & 1960 & 1955 \\
\hline 1990 & 1990 & 1961 & 1956 \\
\hline 1991 & 1992 & 1965 & 1957 \\
\hline 1992 & 1993 & 1966 & 1958 \\
\hline 1995 & 1995 & 1970 & 1959 \\
\hline 1997 & 1997 & 1971 & 1960 \\
\hline 1998 & 1998 & & 1961 \\
\hline & 1999 & & 1962 \\
\hline & & & 1963 \\
\hline & & & 1964 \\
\hline & & & 1965 \\
\hline & & & 1967 \\
\hline & & & 1968 \\
\hline & & & 1970 \\
\hline & & & 1971 \\
\hline
\end{tabular}


JJA (PC01<-0.5)

a) Temperatura da Superficie do Mar

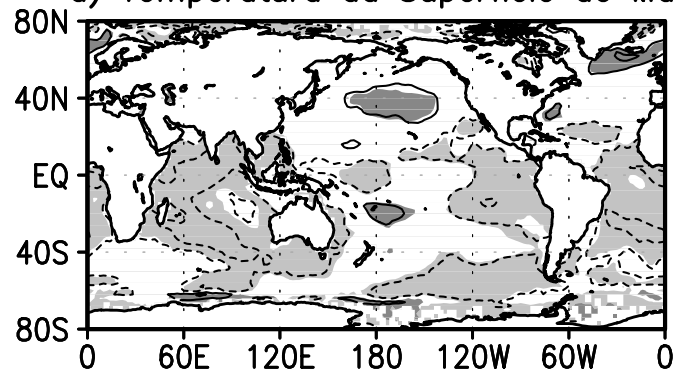

b) Temperatura do ar

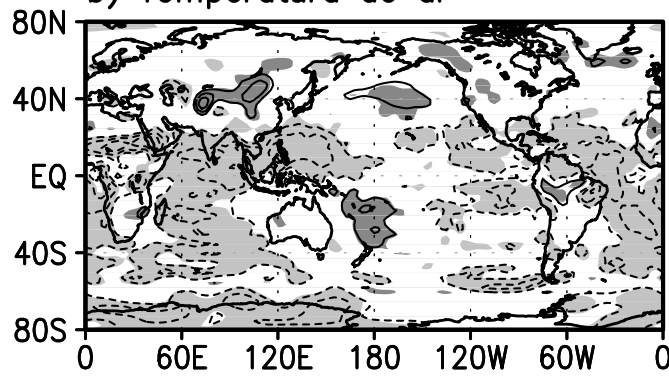

c) Pressao ao Nivel do Mar

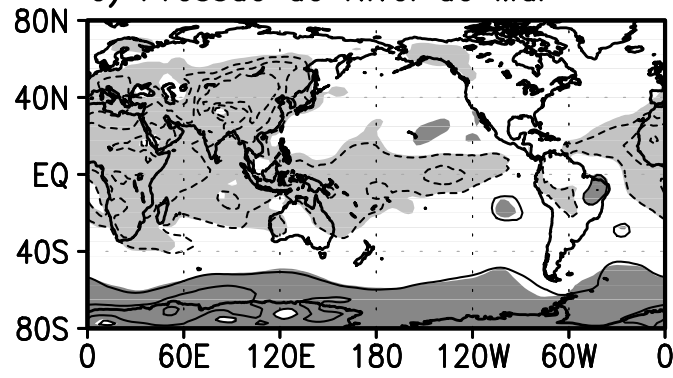

d) Velocidade Vertical

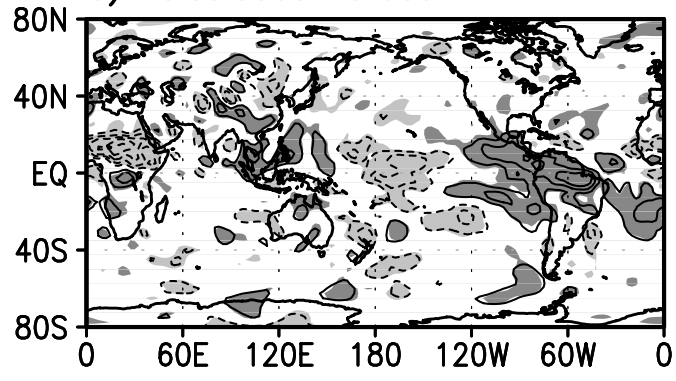

e) Agua Precipitavel

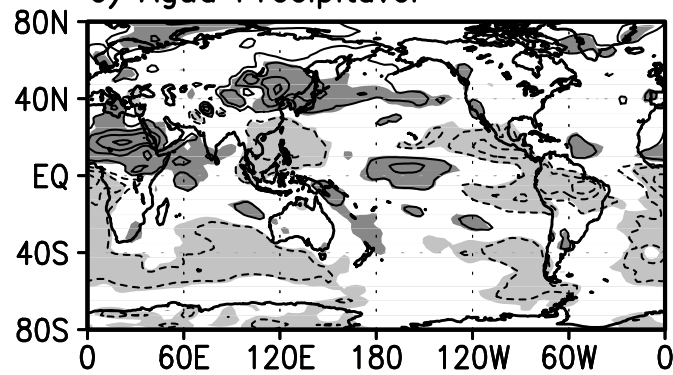

JJA (PC01 > 0.5)

f) Temperatura da Superficie do Mar

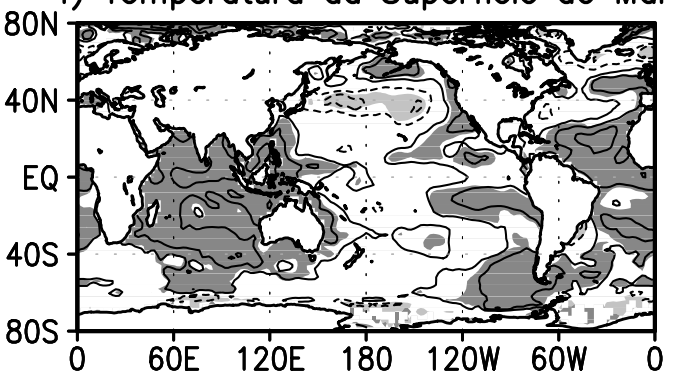

g) Temperatura do ar

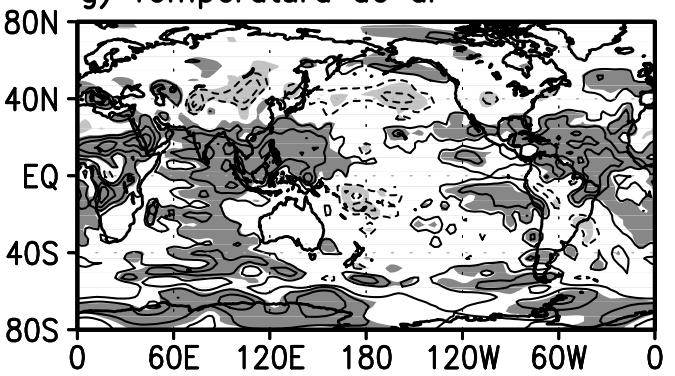

h) Pressao ao Nivel do Mar

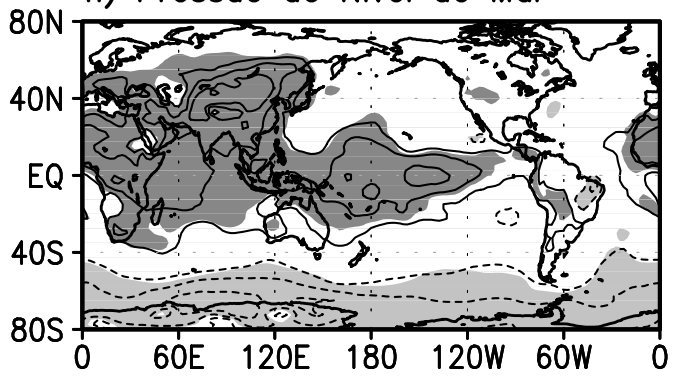

i) Velocidade Vertical
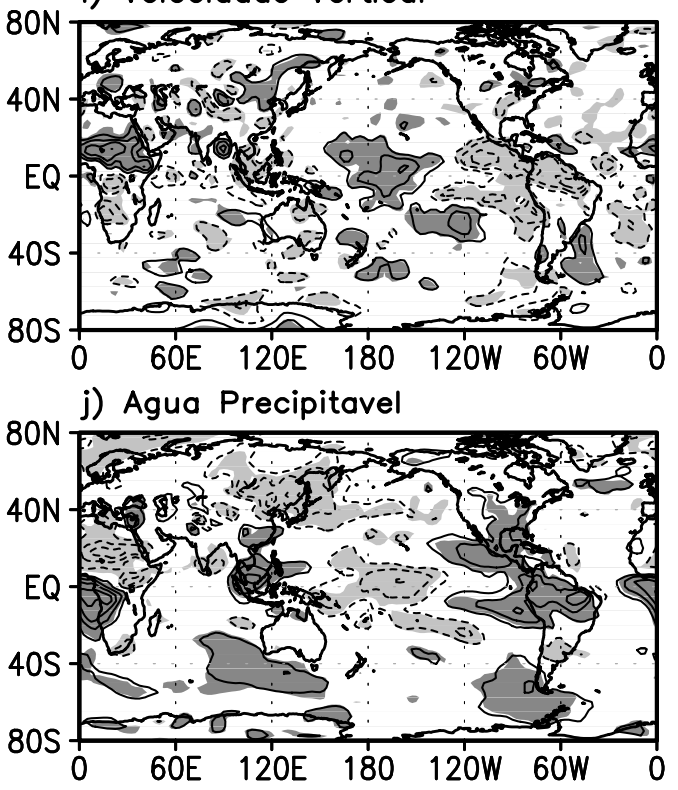

Figura 5 - Compostos das anomalias de inverno (JJA) para PC01 menor que -0,5 desvio padrão para: a) TSM, b) temperatura do ar à superfície, c) PNM, d) velocidade vertical e e) água precipitável. Compostos das anomalias de inverno (JJA) para PC01 maior que 0,5 desvio padrão para: f) TSM, g) temperatura do ar à superfície, h) PNM, j) velocidade vertical e j) água precipitável. As convenções gráficas são as mesmas da Figura 4. 
água precipitável acentuada no oceano Índico tropical sul, no centro do Pacífico tropical norte, e em uma área na costa leste do Brasil (Figura 4e). O composto positivo de água precipitável apresenta padrões quase contrários (Figura 4j).

\subsubsection{Compostos de inverno para o modo MMD}

Em geral, os compostos de inverno apresentam padrões mais suavizados e amplos espacialmente quando comparados aos compostos de verão. O composto negativo (positivo) de inverno das anomalias de TSM, mostra valores menores (maiores) que a normal em grande parte do oceano Índico, no Pacífico leste, no Atlântico equatorial e em grande parte do Atlântico tropical sul (norte) (Figuras 5a e 5f). Consistentemente, o composto negativo (positivo) de temperatura do ar mostra o ar em baixos níveis mais frio (quente) que a média sobre regiões oceânicas mais frias (quentes) que a normal, e sobre as áreas continentais do norte da América do Sul, América Central, sul dos Estados Unidos, México, sul da Índia e na região de monção da África (Figuras $5 \mathrm{~b}$ e $5 \mathrm{~g}$ ). Anomalias de temperatura do ar de sinais opostos são notadas sobre a Mongólia, no Pacífico central norte e em uma pequena área no Pacífico a leste da Austrália.

Similar ao verão, os compostos de inverno das anomalias de PNM apresentam forte estrutura zonal nos trópicos (Figuras 5c e 5h). O composto negativo (positivo) de PNM mostra PNM mais intensa abaixo (acima) da normal sobre a China e o Pacífico equatorial central (Figuras $5 \mathrm{c}$ e $5 \mathrm{~h}$ ), onde o ar à superfície mais quente (frio) que a média é encontrado (Figuras $5 \mathrm{~b}$ e $5 \mathrm{~g}$ ).

Os compostos de inverno de velocidade vertical em 500 hPa e água precipitável são consistentes, ambos apresentando uma onda zonal de número 2 para essas variáveis ao longo de latitudes equatoriais (Figuras 5d, 5e, 5i e 5j). Para o composto negativo de velocidade vertical, movimento ascendente anômalo sobre a região monçônica do oeste da África e sobre o Pacífico equatorial central, é compensado por movimento descendente anômalo sobre o Pacífico equatorial oeste e sobre uma extensa área incluindo o Pacífico equatorial leste, o norte da América do Sul e Atlântico tropical sul e equatorial sul adjacente. O padrão de movimento vertical no Pacífico tropical e no setor América do Sul/Atlântico, é consistente com o padrão de temperatura do ar, de maneira que circulações termicamente diretas podem ser inferidas. $\mathrm{O}$ composto positivo das anomalias de velocidade vertical apresenta um padrão de sinal quase reverso.

Coerentemente, o composto negativo de água precipitável mostra anomalias negativas significantes no setor leste do Atlântico equatorial e sul, no Pacífico equatorial oeste, no oceano Índico sudeste, no Pacífico sudeste, no Pacífico equatorial leste e em grande parte do norte da América do Sul. Este composto também mostra anomalias positivas sobre o setor da África entre o equador e $40^{\circ} \mathrm{N}$, sobre o nordeste da Ásia e oceano Pacífico adjacente e no Pacífico equatorial central (Figura 5e). O composto positivo de inverno de água precipitável apresenta um padrão de sinal quase reverso (Figura $5 \mathrm{j}$ ).

\subsection{Modo Interanual (MIA)}

\subsubsection{Compostos de inverno para o modo MIA}

Para o modo MIA, apenas os compostos de inverno são discutidos, pois para esta estação, a variabilidade interanual é evidente durante todo o período de análise. O fato da variabilidade interanual não ser tão evidente em DJF

Tabela 2 - Anos usados nos compostos para o PC02.

\begin{tabular}{|c|c|c|c|}
\hline \multicolumn{2}{|c|}{ PC02>0,5 } & \multicolumn{2}{|c}{ PC02<-0,5 } \\
\hline DJF (14) & JJA (13) & DJF (13) & JJA (15) \\
\hline 1948 & 1951 & 1971 & 1950 \\
1949 & 1957 & 1975 & 1954 \\
1950 & 1965 & 1978 & 1955 \\
1951 & 1972 & 1983 & 1958 \\
1952 & 1974 & 1984 & 1962 \\
1953 & 1976 & 1985 & 1964 \\
1956 & 1982 & 1987 & 1966 \\
1957 & 1986 & 1988 & 1970 \\
1958 & 1987 & 1989 & 1973 \\
1960 & 1990 & 1992 & 1988 \\
1967 & 1991 & 1993 & 1995 \\
1969 & 1993 & 1995 & 1996 \\
1980 & 1997 & 1998 & 1998 \\
\hline 1982 & & & \\
\hline
\end{tabular}


JJA (PCO2 < -0.5)

a) Temperatura da Superficie do Mar

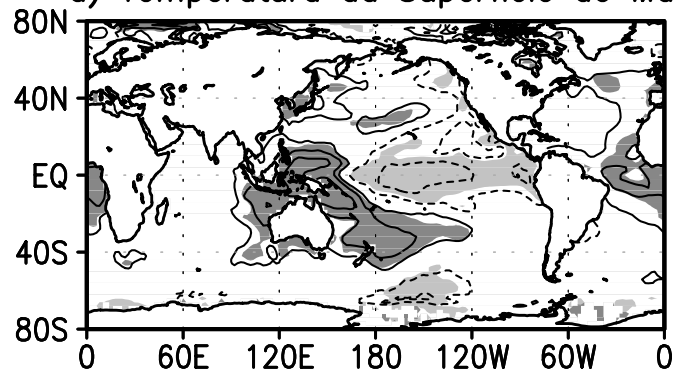

b) Temperatura do ar

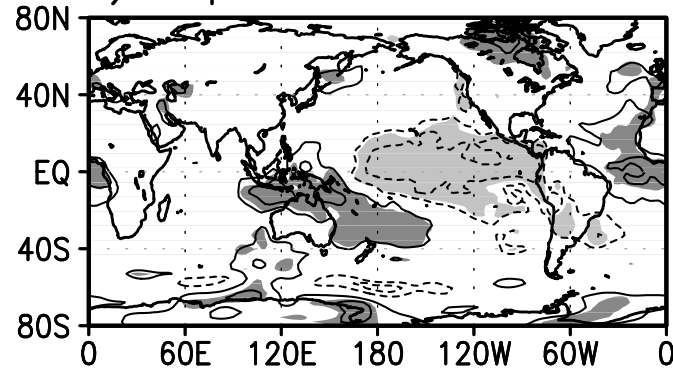

c) Pressao ao Nivel do Mar

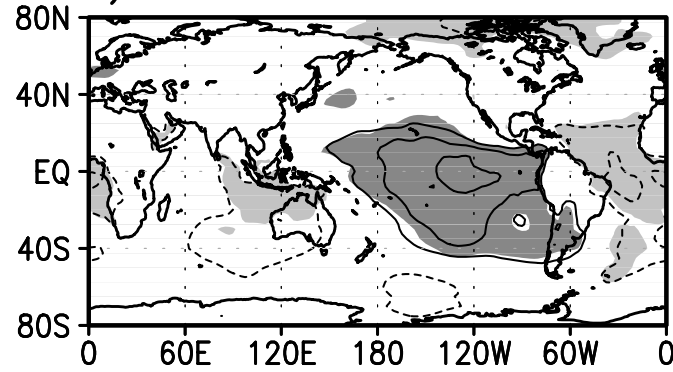

d) Velocidade Vertical

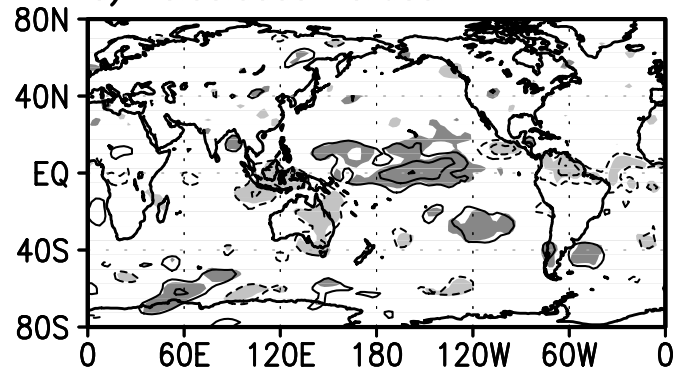

e) Agua Precipitavel

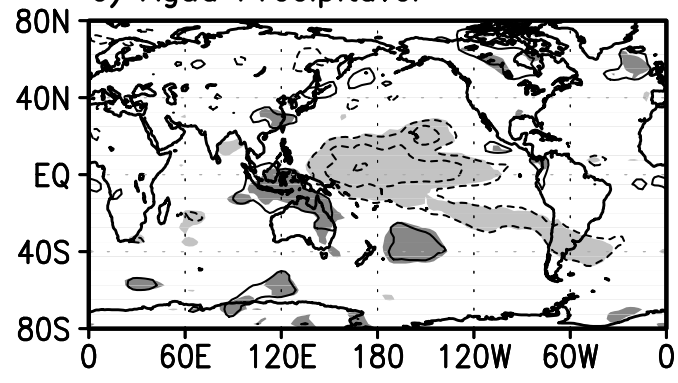

JJA (PCO2 > 0.5)

f) Temperatura da Superficie do Mar

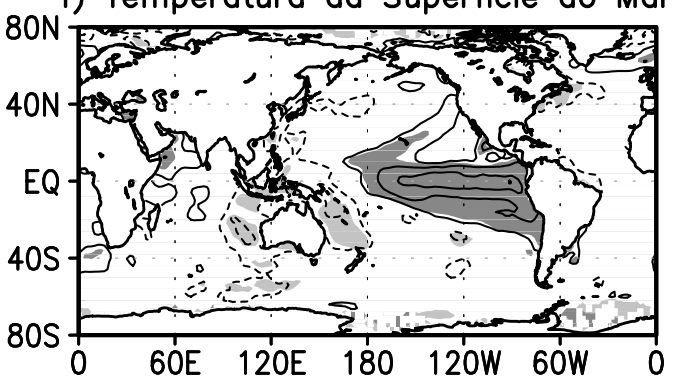

g) Temperatura do ar

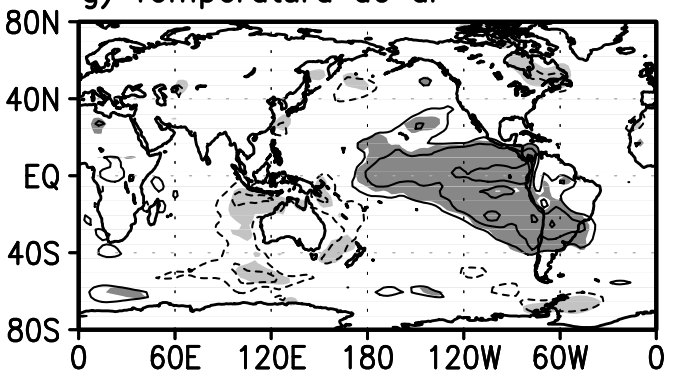

h) Pressao ao Nivel do Mar
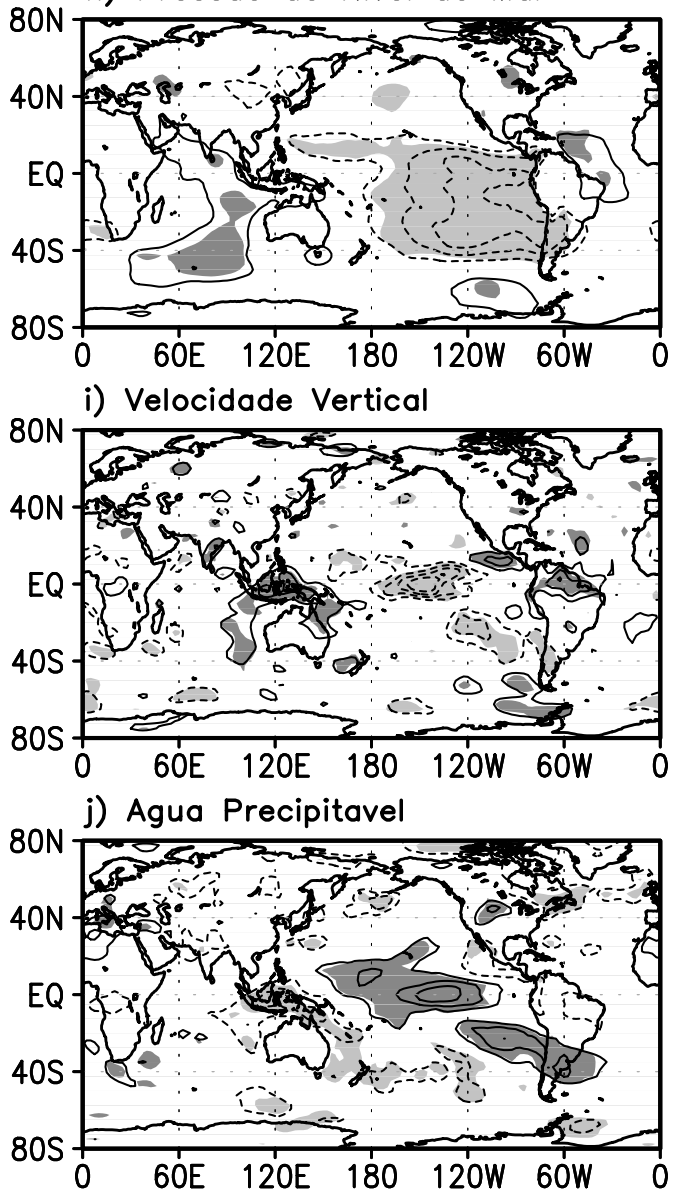

Figura 6 - Compostos das anomalias de inverno (JJA) para PC02 menor que -0,5 desvio padrão para: a) TSM, b) temperatura do ar à superfície, c) PNM, d) velocidade vertical e e) água precipitável. Compostos das anomalias de inverno (JJA) para PC02 maior que 0,5 desvio padrão para: f) TSM, g) temperatura do ar à superfície, h) PNM, j) velocidade vertical e j) água precipitável. As convenções gráficas são as mesmas da Figura 4. 
é consistente com trabalhos anteriores, visto que o impacto de eventos ENOS no verão do Brasil, por exemplo, mostra forte variação subsazonal, resultando em médias sazonais que suavizam as anomalias significativas de verão (Grimm, 2003; 2004; Grimm et al., 2007). Assim, esses trabalhos sugerem que os processos regionais são mais importantes quando comparados a influências remotas no verão sobre a América do Sul.

Similar à análise anterior, os valores limítrofes de $\pm 0,5$ desvio padrão do PC02 sazonal são usados para selecionar os casos dos compostos. Os compostos negativos (positivos) referem-se aos casos com PC02 menores que -0,5 (maiores que 0,5$)$ desvio padrão. Esses compostos não são separados de acordo com as fases da ODP. A Tabela 2 lista os anos considerados nos compostos.

O composto negativo das anomalias de TSM captura o padrão ENOS. Esse composto mostra água mais fria que a normal no Pacífico equatorial central e leste, água mais quente que a normal nos setores equatorial e subtropical do Pacífico oeste e anomalias reduzidas de TSM nos outros lugares (Figura 6a). O composto positivo das anomalias de TSM mostra padrões semelhantes, mas com sinal reverso (Figura 6f). Os compostos de anomalias de temperatura do ar à superfície ilustram padrões bem similares, exceto por anomalias negativas (positivas) menos confinadas equatorialmente no Pacífico leste (Figuras $6 \mathrm{~b}$ e $6 \mathrm{~g})$.

Consistente com os padrões de TSM e temperatura do ar à superfície, os compostos das anomalias de PNM mostram as maiores magnitudes nos trópicos com uma estrutura zonal de onda número 1 para essa variável (Figuras 6c e 6h). Para o composto positivo, PNM acima da normal é notada no Pacífico tropical leste e PNM abaixo da normal estende-se da banda no Atlântico entre $20^{\circ} \mathrm{N}$ e $20^{\circ} \mathrm{S}$ ao oceano Índico tropical. Esse padrão apresenta algumas similaridades com o modo Oscilação Sul de PNM. O composto negativo de PNM mostra um padrão semelhante, mas com sinal reverso.

Os compostos de velocidade vertical apresentam anomalias significativas espalhadas em pequenas áreas do Pacífico tropical (Figuras 6d e 6i). Para o composto negativo (positivo), movimento descendente (ascendente) anômalo é encontrado em pequenas áreas do Pacífico equatorial e

a) Indice Monconico - ODP

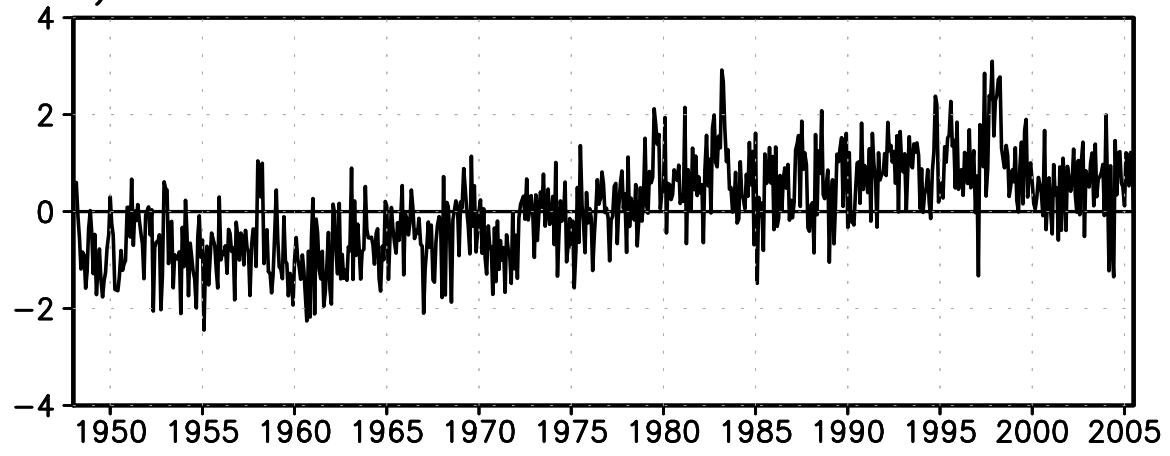

b) Indice ENOS

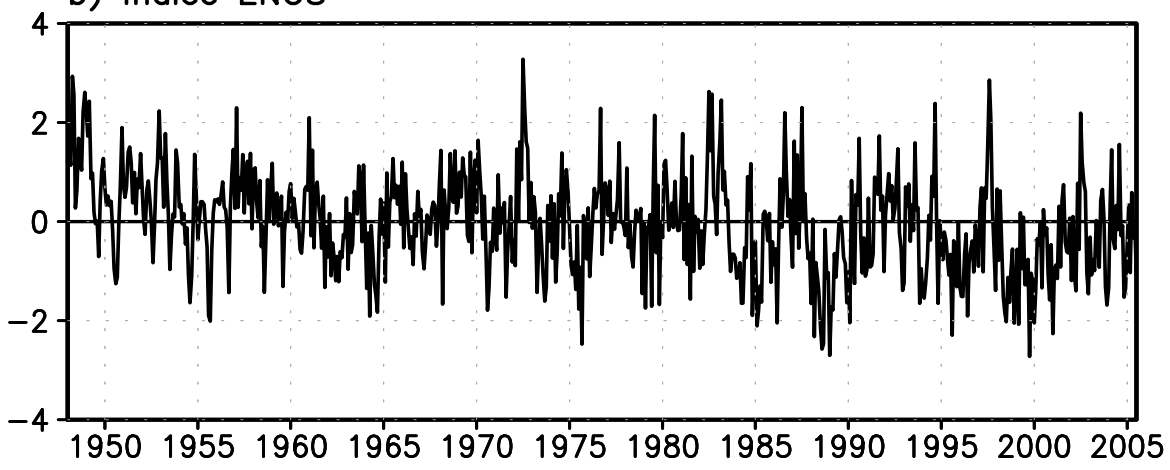

Figura 7 - Série temporal do (a) índice monçônico relacionado à ODP (IMP) e (b) índice relacionado ao ENOS (IEN). 
movimento ascendente (descendente) anômalo sobre Papua/ Nova Guiné. Os compostos das anomalias de água precipitável mostram padrões consistentes (Figuras 6e e 6j). Para o composto negativo, anomalias positivas de água precipitável estendem-se zonalmente do oceano Índico equatorial sul em direção a área de Papua/Nova Guiné, e anomalias negativas de água precipitável são notadas no Pacífico equatorial central e no Pacífico sudeste. O composto positivo de água precipitável ilustra anomalias negativas sobre a área de Papua/Nova Guiné e anomalias positivas no Pacífico equatorial central e no Pacífico sudeste. Os padrões das anomalias de água precipitável são dinamicamente e termodinamicamente consistentes com os padrões das anomalias de PNM, TSM e temperatura do ar à superfície.

\section{4 Índices para monitoramento}

A análise da EOF do $\chi$-transiente separa a variabilidade dessa variável nas escalas de tempo multi-decenal e interanual no primeiro e segundo modo, respectivamente. O primeiro modo mostra a maior variância regional do $\chi$-transiente na América do Sul e no Pacífico oeste, descrevendo aspectos do sistema monçônico da América do Sul, como visto nos compostos. O

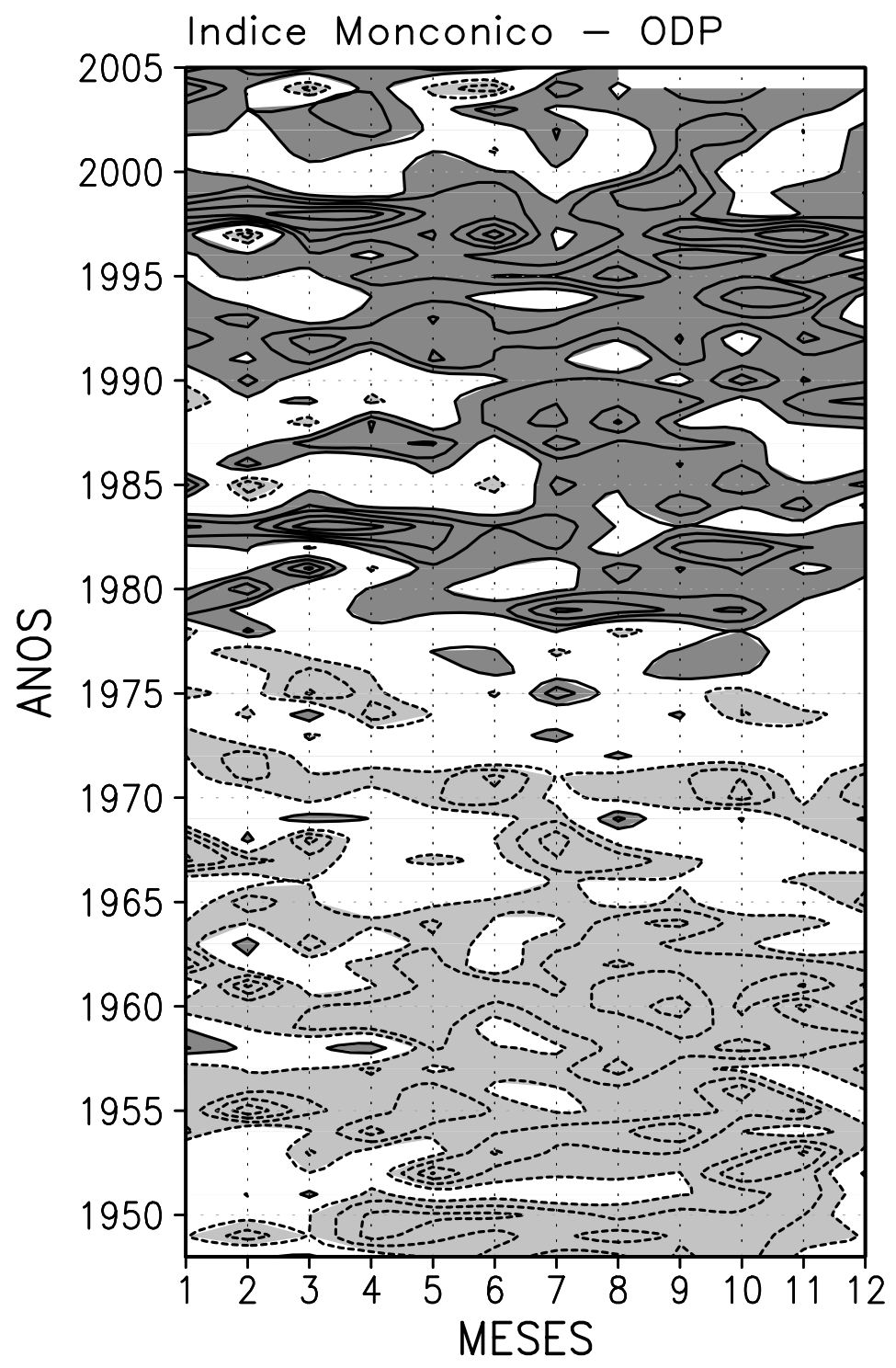

Figura 8 - Gráfico de meses versus ano do índice monçônico relacionado à ODP. O intervalo de contorno é de 0,5 desvio padrão com contornos negativos (positivos) tracejados (contínuos). O contorno de zero foi omitido. Áreas hachuradas claras (escuras) indicam valores menores (maiores) que $-0,5(0,5)$. 
segundo modo descreve a variabilidade interanual relacionada ao ENOS, também notado nos compostos, com a maior variância regional do $\chi$-transiente na região dos Estados Unidos, México e Pacífico leste e na região da Ásia, África e oceano Índico. Para fins de monitoramento, índices baseados nos padrões das configurações espaciais do primeiro e segundo modo da EOF são propostos. Índices são obtidos pela projeção do campo de anomalia de $\chi$-transiente nos padrões das configurações espaciais desses modos, o que significa que esses índices são os coeficientes de correlação entre tais campos. Um índice monçônico relacionado à ODP (IMP) e um índice relacionado ao ENOS (IEN) baseados respectivamente nos padrões das configurações espaciais do primeiro e segundo modo são obtidos para o período de janeiro de 1948 a julho de 2005 (Figuras 7a e 7b). Esses índices para o período de 1948-1999 reproduzem a série temporal do PC correspondente. A eficiência desses índices para propósitos de monitoramento é explorada através de seus gráficos de anos versus meses.

O gráfico de anos versus meses do IMP mostra dominância de valores negativos antes de meados da década de 1970 e de valores positivos depois. Essa persistência de longo prazo de mesmo sinal dos valores do IMP é mais evidente durante o inverno. Outro aspecto interessante é que a alteração climática brusca multi-decenal ocorre dentro de um período de transição de aproximadamente 5 anos, com valores de IMP relativamente pequenos ou de sinais contrários. Além disso, os pequenos valores de IMP durante 2001 e os negativos durante março e maio de 2005 podem ser as primeiras indicações de um período de transição eminente.

Os valores do IEN para os meses de verão e outono mostram dominância de valores positivos antes de 1960 e de valores negativos de 1984 em diante (Figura 9). Por outro lado,

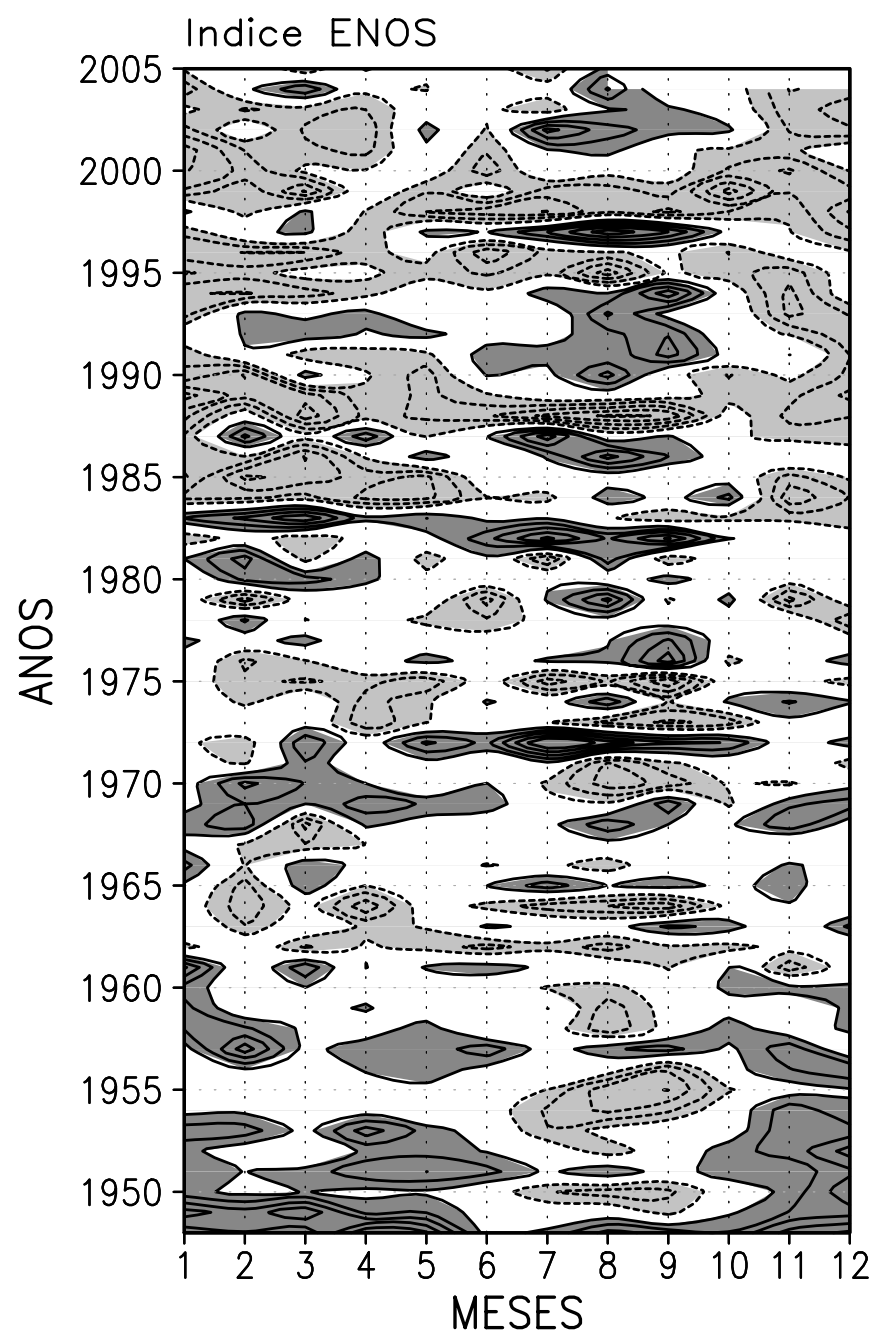

Figura 9 - Gráfico de meses versus ano do índice relacionado ao ENOS. As convenções gráficas são as mesmas da Figura 8. 
os valores de IEN para os meses de junho a outubro mostram forte variabilidade interanual. Esses resultados indicam a presença das componentes decenal e interanual na EOF02, cujas manifestações são sazonalmente dependentes.

\section{CONCLUSÕES}

Os dados de temperatura da superfície do mar (TSM) e os campos reanalisados de potencial de velocidade $(\chi)$ em $200 \mathrm{hPa}$, temperatura do ar à superfície, pressão ao nível do mar (PNM), velocidade vertical em $500 \mathrm{hPa}$ e água precipitável são utilizados para examinar a variabilidade dos sistemas monçônicos durante o período de 1948-1999. A componente monçônica de $\chi$ em 200 $\mathrm{hPa}$ ( $\chi$-transiente), o desvio da média anual do campo de desvio zonal (Tanaka et al., 2004), é o parâmetro chave usado aqui para examinar a variabilidade espacial e temporal das monções. Essa variabilidade é obtida através da análise de EOF das anomalias mensais (de todo o ano) do $\chi$-transiente na banda global entre $60^{\circ} \mathrm{Ne} 40^{\circ} \mathrm{S}$. Os padrões das anomalias para as outras variáveis são obtidos da técnica de composição para as estações de verão e inverno.

A análise de EOF do $\chi$-transiente fornece dois modos separados. O modo mais energético captura principalmente, a variabilidade multi-decenal dos sistemas monçônicos na América do Sul e no Pacífico oeste (Figura 1). Esse modo mostra um escoamento convergente (divergente) anômalo sobre a América do Sul tropical e oceano Atlântico adjacente, e um escoamento divergente (convergente) sobre o Pacífico oeste antes (depois) de 1975. Esse modo, chamado aqui de modo monçônico multi-decenal (MMD), é bastante similar ao modo tropical multi-decenal obtido por Chelliah e Bell (2004) como o primeiro modo da análise de EOF de verão do potencial de velocidade em $200 \mathrm{hPa}$ filtrado com o filtro passa-baixa (Figura $4 \mathrm{c}$ deles). Diferente dos resultados obtidos por eles, nossa análise mostra que o modo MMD ocorre todo o ano. Em adição, como o modo MMD é baseado em dados não filtrados, oscilações de mais alta freqüência são superimpostas às oscilações multidecenais desse modo.

Os padrões das anomalias de TSM associados com o modo MMD para verão e inverno (Figuras 4a, 4f, 5a e 5f) são bastante similares ao padrão das anomalias de TSM do modo ODP descrito por Mantua et al. (1997). Assim, tem-se que o modo MMD contém a variabilidade multi-decenal relacionada à dinâmica da ODP. Os padrões anômalos associados com o modo MMD para todas as variáveis, mostram forte coerência espacial e consistência dinâmica e termodinâmica entre eles. Esses resultados garantem a robustez do modo MMD. A interpretação para a América do Sul tropical e o setor do Atlântico, é que na fase negativa (positiva) da ODP ocorrida antes (depois) de 1975, o ar frio (quente) anômalo em baixos níveis estabelecido nesse setor é acompanhado por movimento descendente (ascendente) anômalo e escoamento convergente (divergente) em altos níveis, indicando assim, o enfraquecimento (fortalecimento) do sistema de monção da América do Sul como mostrado nos compostos de água precipitável. O fortalecimento da monção na América do Sul depois de 1975 é consistente com o aumento da precipitação observado sobre a bacia Amazônica durante o período 1980-1990 relativo ao período 1950-1960 (Chu et al., 1994; Kumar et al., 1999; Chen et al., 2001). O fato de, esses estudos serem baseados em registros instrumentais de precipitação, faz com que os resultados obtidos com os dados da reanálise do NCEP estejam fundamentados, pelo menos no que concerne à América do Sul tropical.

O segundo modo descreve as variações interanuais opostas entre a área que compreende os Estados Unidos, México e Pacífico oeste e a região da Ásia, África e oceano Índico (Figura 2). Esse modo, chamado aqui de modo interanual (MIA), apresenta algumas similaridades com o modo tropical interanual (ENOS) determinado por Chelliah e Bell (2004), como o primeiro modo da análise da EOF de inverno do potencial de velocidade em $200 \mathrm{hPa}$ filtrado com o filtro passa-baixa (Figura 3d deles). Os padrões anômalos de TSM, temperatura do ar à superfície, PNM, velocidade vertical e água precipitável são bastante similares aos padrões relacionados ao ENOS. Os padrões de sinais opostos para as variáveis de circulação e termodinâmicas sobre a Índia e o oeste dos Estados Unidos/México confirmam resultados anteriores sobre os efeitos do ENOS nessas regiões (e.g., Ropelewski e Halpert, 1987; 1989).

Índices baseados nas configurações espaciais desses modos, são propostos aqui para fins de monitoramento. O índice monçônico relacionado à ODP (IMP) e o índice relacionado ao ENOS (IEN) são baseados nas configurações espaciais do primeiro e segundo modo, respectivamente. O IMP, em particular parece ter algum potencial para o uso em propósitos de monitoramento. A análise desse índice indica, que a alteração climática brusca multi-decenal ocorre dentro de um período de transição de aproximadamente 5 anos, com valores de IMP relativamente pequenos ou de sinal contrário. Considerando esse aspecto, tem-se que os pequenos valores de IMP durante 2001 e os valores negativos em março e maio de 2005 , podem ser indícios de um período de transição eminente.

\section{AGRADECIMENTOS}

Os autores foram parcialmente financiados pelo Conselho Nacional de Desenvolvimento Científico e Tecnológico (CNPq). Esse trabalho é parte da dissertação de mestrado da primeira autora. Os autores agradecem aos revisores pelas valiosas sugestões na primeira versão desse trabalho. 


\section{REFERÊNCIAS BIBLIOGRÁFICAS}

ANDREOLI, R. V.; KAYANO, M. T. ENSO-related rainfall anomalies in South America and associated circulation features during warm and cold Pacific decadal oscillation regimes. International Journal of Climatology, v. 25, p. 2017-2030, 2005.

BARLOW, M.; NIGAM, S.; BERBERY, E. H. ENSO, Pacific decadal variability, and U.S. summertime precipitation, drought, and streamflow. Journal of Climate, v. 14, p. $2105-$ 2128, 2001.

BROWN, D. J.; COMRIE, A. C. A winter precipitation 'dipole' in the western United States associated with multidecadal ENSO variability. Geophysical Research Letters, v. 31, p. L09203.1-L09203.4, 2004.

CASTRO, C. L.; MCKEE, T. B.; PIELKE, Sr. R. A. The relationship of the North American monsoon to tropical and North Pacific sea surface temperatures as revealed by observational analyses. Journal of Climate, v. 14, p. 44494473, 2001.

CHELLIAH, M.; BELL, G. D. Tropical multidecadal and interdecadal climate variability in the NCEP-NCAR reanalysis. Journal of Climate, v. 17, p. 1777-1803, 2004.

CHANG, C-P.; ZHANG, Y.; LI, T. Interannual and interdecadal variations of the east Asia summer monsoon and tropical Pacific SSTs. Part I: roles of the subtropical ridge. Journal of Climate, v. 13, p. 4310-4325, 2000a.

CHANG, C-P.; ZHANG, Y.; LI, T. Interannual and interdecadal variations of the east Asia summer monsoon and tropical Pacific SSTs. Part II: Meridional structure of the monsoon. Journal of Climate, v. 13, p. 4326-4340, 2000b.

CHEN, T-C.; YOON, J-H.; ST. CROIX, K. J.; TAKLE, E. S. Suppressing impacts of the Amazonian deforestation by the global circulation change. Bulletin of the American Meteorological Society, v. 82, p. 2209-2216, 2001.

CHU, P-S.; YU, Z-P.; HASTENRATH, S. Detecting climate change concurrent with deforestation in the Amazon Basin: Which way has it gone? Bulletin of the American Meteorological Society, v. 75, p. 579-583, 1994.

DIAS DE PAIVA, E. M. C.; CLARKE, R. T. Time trends in rainfall records in Amazonia. Bulletin of the American Meteorological Society, v. 76, p. 2203-2209, 1995.

DING, Y.; WANG, H.; WANG, B. East Asian summer monsoon. In: THE GLOBAL MONSOON SYSTEM: RESEARCH AND FORECAST. C.-P. Chang, B. Wang and N.-C. G. Lau, Eds., WMO/TD n. 1266 - TMRP Report n. 70, p. 95-114, 2005. Disponível em http://www.wmo.int/pages/prog/arep/ tmrp/documents/global_monsoon_system_IWM3.pdf

GARREAUD, R. D.; BATTISTI, D. S. Interannual (ENSO) and interdecadal (ENSO-like) variability in the Southern Hemisphere tropospheric circulation. Journal of Climate, v. 12, p. 2113-2123, 1999.

GERSHUNOV, A.; BARNETT, T. P. Interdecadal modulation of ENSO teleconnections. Bulletin of the American Meteorological Society, v. 79, p. 2715-2725, 1998.

GOSWAMI, B. N. South Asian Summer monsoon: An Overview. In: THE GLOBAL MONSOON SYSTEM: RESEARCH AND FORECAST. C.-P. Chang, B. Wang and N.-C. G. Lau, Eds., WMO/TD n. 1266 - TMRP Report n. 70, p. 47-71, 2005. Disponível em http:/www.wmo.int/pages/prog/arep/ tmrp/documents/global_monsoon_system_IWM3.pdf

GRIMM, A. M. The El Niño Impact on the Summer Monsoon in Brazil: Regional Processes versus Remote Influences. Journal of Climate, v. 16, p. 263-280, 2003.

GRIMM, A. M. How do La Niña events disturb the summer monsoon system in Brazil? Climate Dynamics, v. 22, n. 2-3, p. 123-138, 2004.

GRIMM, A. M.; VERA, C. S.; MECHOSO, C. R. The South American Monsoon System. In: THE GLOBAL MONSOON SYSTEM: RESEARCH AND FORECAST. C.-P. Chang, B. Wang and N.-C. G. Lau, Eds., WMO/TD n. 1266 - TMRP Report n. 70, p. 219-238, 2005. Disponível em http:/www.wmo.int/pages/prog/arep/tmrp/documents/ global_monsoon_system_IWM3.pdf

GRIMM, A. M.; PAL, J. S.; GIORGI, F. Connection between Spring Conditions and Peak Summer Monsoon Rainfall in South America: Role of Soil Moisture, Surface Temperature, and Topography in Eastern Brazil. Journal of Climate, v.20, p. 5929-5945, 2007.

GUTZLER, D. S.; KANN, D. M.; THORNBRUGH, C. Modulation of ENSO-based long-lead outlooks of southwestern U.S. winter precipitation by the Pacific decadal oscillation. Weather and Forecasting, v. 17, p. 1163-1172, 2002.

HIGGINS, R. W.; SHI, W. Dominant factors responsible for interannual variability of the summer monsoon in the Southwestern United States. Journal of Climate, v. 13, p. 759-776, 2000.

HU, Z-Z. Interdecadal variability of summer climate over East Asia and its association with $500 \mathrm{hPa}$ height and global sea surface temperature. Journal of Geophysical Research, v. 102, p. 19403-19412, 1997.

KALNAY, E.; AND CO-AUTHORS. The NCEP/NCAR reanalysis project. Bulletin of the American Meteorological Society, v. 77, p. 437-471, 1996.

KAYANO, M. T.; ANDREOLI, R. V. Decadal variability of northern northeast Brazil rainfall and its relation to tropical sea surface temperature and global sea level pressure anomalies. Journal of Geophysical Research, v. 109, n. 
C11011, doi: 10.1029/2004JC002429, 2004.

KAYANO, M.T.; KOUSKY, V.E. An index of low-frequency variability in the global tropics. In: 17th ANNUAL CLIMATE DIAGNOSTICS WORKSHOP, 1992, Norman, Oklahoma. Proceedings..., 1993, p. 341-347.

KREPPER, C. M.; SEQUEIRA, M. E. Low frequency variability of rainfall in southeastern South America. Theoretical and Applied Climatology, v. 61, p. 19-28, 1998.

KRISHNAMURTI, T. N. Tropical east-west circulations during the northern summer. Journal of the Atmospheric Sciences, v. 28, p. 1342-1347, 1971.

KRISHNAMURTI, T. N.; KANAMITSU, M.; KOSS, W. J.; LEE, J. D. Tropical east-west circulations during the northern winter. Journal of the Atmospheric Sciences, v. 30, p. 780-787, 1973.

KRISHNAMURTHY, V.; GOSWAMI, B. N. Indian monsoonENSO relationship on interdecadal timescale. Journal of Climate, v. 13, p. 579-595, 2000.

KUMAR, K. K.; RAJAGOPALAN, B.; CANE, M. A. On the weakening relationship between the Indian monsoon and ENSO. Science, v. 284, p. 2156-2159, 1999.

LAU, K. M.; LI, M. T. The monsoon of East Asia and its global association - A survey. Bulletin of the American Meteorological Society, v. 65, p. 114-125, 1984.

LIU, Z.; WU, L.; GALLIMORE, R.; JACOB, R. Search for the origins of Pacific decadal climate variability. Geophysical Research Letters, v. 29, p. 42.1-42.4, 2002.

MANTUA, N.; HARE, S.; ZHANG, Y.; WALLACE, J. M.; FRANCIS, R. A Pacific interdecadal climate oscillation with impacts on salmon production. Bulletin of the American Meteorological Society, v. 78, p. 1069-1079, 1997.

MARENGO, J. A. Interdecadal variability and trends of rainfall across the Amazon basin. Theoretical and Applied Climatology, v. 78, p. 79-96, 2004.

MCCABE, G. J.; DETTINGER, M. D. Decadal variations in the strength of ENSO teleconnections with precipitation in the western United States. International Journal of Climatology, v. 19, p. 1399-1410, 1999.

MECHOSO, C. R.; ROBERTSON, A. W.; ROPELEWSKI, C. F.; GRIMM, A. M. The American Monsoon Systems: an Introduction. In: THE GLOBAL MONSOON SYSTEM: RESEARCH AND FORECAST. C.-P. Chang, B. Wang and N.-C. G. Lau, Eds., WMO/TD n. 1266 - TMRP Report n. 70, p. 197-206, 2005. Disponível em http://www.wmo. int/pages/prog/arep/tmrp/documents/global_monsoon_ system_IWM3.pdf

MESTAS-NUÑEZ, A. M.; ENFILED, D. B. Eastern equatorial Pacific SST variability: ENSO and non-ENSO components and their climate associations. Journal of Climate, v. 14, p. 391-402, 2001.
MINOBE, S. Resonance in bidecadal and pentadecadal climate oscillations over the North Pacific: role in climatic regime shifts. Geophysical Research Letters, v. 26, p. 855-858, 1999.

MINOBE, S. Spatio-temporal structure of the pentadecadal variability over the North Pacific. Progress in Oceanography, v. 47, p. 381-408, 2000.

MO, K. C.; HAKKINEN, S. Decadal variations in the Tropical South Atlantic and linkages to Pacific. Geophysical Research Letters, v. 28, p. 2065-2068, 2001.

MOOLEY, D. A.; PARTHASARATHY, B. Fluctuations in allIndia summer monsoon rainfall during 1871-1978. Climate Change, v. 6, p. 287-301, 1984.

NORTH, G. R.; BELL, T. L.; CAHALAN, R. F.; MOENG, F. J. Sampling errors in the estimation of empirical orthogonal function. Monthly Weather Review, v. 110, p. 699-706, 1982.

PAEGLE, J. N.; MO, K. C. Linkages between summer rainfall variability over South America and sea surface temperature anomalies. Journal of Climate, v. 15, p. 1389-1407, 2002.

PAEGLE, J. N.; AND CO-AUTHORS. Progress in Pan American CLIVAR research: understanding the South American Monsoon. Meteorologica, v. 27, p. 3-30, 2002.

PANOFSKY, H. A.; BRIER, G. W. Some Applications of Statistics to Meteorology. Pennsylvania State University, 1968. 224p.

PARTHASARATHY, B.; MUNOT, A. A.; KOTHAWALE, D. R. All-India monthly and seasonal rainfall series: 1871-1993. Theoretical and Applied Climatology, v. 49, p. 217-224, 1994.

ROBERTSON, A. W.; MECHOSO, C. R. Interannual and decadal cycles in river flows of southeastern South America. Journal of Climate, v. 11, p. 2570-2581, 1998.

ROBERTSON, A. W.; MECHOSO, C. R. Interannual and interdecadal variability of the South Atlantic convergence zone. Monthly Weather Review, v. 128, p. 2947-2957, 2000.

ROPELEWSKI, C. F.; HALPERT, M. S. Global and regional scale precipitation patterns associated with the El Niño/ Southern Oscillation. Monthly Weather Review, v. 115, p. 1606-1626, 1987.

ROPELEWSKI, C. F.; HALPERT, M. S. Precipitation patterns associated with the high index phase of the Southern Oscillation. Journal of Climate, v. 2, p. 268-284, 1989.

ROPELEWSKI, C. F.; GUTZLER, D. S.; HIGGINS, R. W.; MECHOSO, C. R. The North American Monsoon System. In: THE GLOBAL MONSOON SYSTEM: RESEARCH AND FORECAST. C.-P. Chang, B. Wang and N.-C. G. Lau, Eds., WMO/TD n. 1266 - TMRP Report n. 70, p. 207-218, 2005. Disponível em http://www.wmo.int/pages/prog/arep/ 
tmrp/documents/global_monsoon_system_IWM3.pdf

SMITH, T. M.; REYNOLDS, R. W. Extended reconstruction of global sea surface temperatures based on COADS data (1854-1997). Journal of Climate, v. 16, p. 1495-1510, 2003.

TANAKA, H. L.; ISHIZAKI, N.; KITOH, A. Trend and interannual variability of Walker, monsoon and Hadley circulations defined by velocity potential in the upper troposphere. Tellus, v. 56A, p. 250-269, 2004.

TAO, S. Y.; CHEN, L. A review of recent research on the East Asian summer monsoon in China. Monsoon Meteorology, C.-P. Chang and T. N. Krishnamurti, eds, Oxford University Press, p. 60-92, 1987.

WANG, B.; LI, T.; DING, Y.; ZHANG, R.; WANG, H. East Asian-Western North Pacific Monsoon: A Distinctive Component of the Asian-Australian Monsoon System. In: THE GLOBAL MONSOON SYSTEM: RESEARCHAND
FORECAST. C.-P. Chang, B. Wang and N.-C. G. Lau, Eds., WMO/TD n. 1266 - TMRP Report n. 70, p. 72-94, 2005. Disponível em http://www.wmo.int/pages/prog/arep/tmrp/ documents/global_monsoon_system_IWM3.pdf

WU, R.; WANG, B. A contrast of the East Asian summer monsoon-ENSO relationship between 1962-77 and 1978-93. Journal of Climate, v. 15, p. 3266-3279, 2002.

ZHANG, Y.; WALLACE, J. M.; BATTISTI, D. ENSO-like interdecadal variability: 1900-93. Journal of Climate, v. 10, p. 1004-1020, 1997.

ZHANG, Y.; NORRIS, J.; WALLACE, J. M. Seasonality of large-scale atmosphere-ocean interaction over the North Pacific. Journal of Climate, v. 11, p. 2473-2481, 1998.

ZHOU, J.; LAU, K. M. Principal modes of interannual and decadal variability of summer rainfall over South America. International Journal of Climatology, v. 21, p. 1623-1644, 2001. 